(C) 2018, American Psychological Association. This paper is not the copy of record and may not exactly replicate the final, authoritative version of the article. Please do not copy or cite without authors' permission. The final article will be available, upon publication, via its DOI: 10.1037/aca0000224

Order, Complexity, and Aesthetic Appreciation

Eline Van Geert and Johan Wagemans

KU Leuven, Belgium

Author Note

Eline Van Geert, Laboratory of Experimental Psychology, Department of Brain and Cognition, KU Leuven (University of Leuven), Belgium; Johan Wagemans, Laboratory of Experimental Psychology, Department of Brain and Cognition, KU Leuven (University of Leuven), Belgium.

This work has been supported by long-term structural funding from the Flemish Government awarded to Johan Wagemans (METH/14/02).

Correspondence concerning this article should be addressed to Eline Van Geert, Laboratory of Experimental Psychology, KU Leuven (University of Leuven), Tiensestraat 102 - bus 3711, 3000 Leuven. Telephone: +32 163734 80. E-mail:

eline.vangeert@kuleuven.be 


\begin{abstract}
Which stimulus and person characteristics determine aesthetic appreciation? For many centuries, philosophers and scientists have been trying to solve this complex puzzle. Through the ages, order, complexity, and the balance between order and complexity have frequently been considered as an answer to this question. The literature on the topic, however, both theoretically and empirically speaking, is rather diffuse and contradictory. In this review, we give an overview of the main theories and empirical findings relating order, complexity, and their interplay to aesthetic appreciation, focusing on research concerning the visual modality. Additionally, we propose our own view on the interplay between order and complexity, in line with the reviewed theories and findings. Besides general relations, also individual differences in order, complexity, aesthetic appreciation, and their interrelations are discussed. With this review, we hope to conceptually clarify the literature and point to new roads for investigation in the field of human aesthetics.
\end{abstract}

Keywords: aesthetics, order, complexity, individual differences 
Order, Complexity, and Aesthetic Appreciation

Complexity without order produces confusion. Order without complexity causes boredom. (Arnheim, 1966, p. 124)

We must ultimately be able to account for the most basic fact of aesthetic experience, the fact that delight lies somewhere between boredom and confusion. (Gombrich, 1984/1992, p. 9)

Which stimulus and person characteristics determine aesthetic appreciation? For many centuries, philosophers and scientists have been trying to solve this complex puzzle. Order, complexity, and the balance between order and complexity have frequently been considered as an answer to this question. In a first part of this review, we focus on the main theories and findings concerning the general relations between (a) complexity and aesthetic appreciation; (b) order and aesthetic appreciation; and (c) the balance between order and complexity and aesthetic appreciation. In a second part, we focus on theories and findings concerning (d) individual variability in the interplay between order, complexity, and aesthetic appreciation. Finally, we give (e) some considerations for future research.

\section{Complexity and Aesthetic Appreciation}

As will become clear in our review of the literature on this topic, the term complexity has been used to refer to a whole plethora of different stimulus aspects and has been defined in very diverse ways (for an extensive review of visual complexity, see Donderi, 2006a). We will define (stimulus) complexity as those aspects related to the quantity and variety of information (in a stimulus).

\section{Differential relationships between complexity and aesthetic appreciation.}

Although a lot of studies support the importance of complexity in shaping aesthetic preferences (e.g., Jacobsen \& Höfel, 2002; Jacobsen, Schubotz, Höfel, \& von Cramon, 2006; Tinio \& Leder, 2009), studies do not agree on the type and direction of the relationship (Nadal, Munar, Marty, \& Cela-Conde, 2010). Berlyne (1971) predicted that stimuli with a moderate level of complexity would be preferred above those with low or high levels of complexity. Many studies support Berlyne's hypothesis of an inverted U-shaped relationship between complexity and aesthetic preference, with highest preference for stimuli with an intermediate level of complexity (e.g., for music: North \& Hargreaves, 1995; Gordon \& Gridley, 2013; for line drawings of house facades: Imamoglu, 2000; for language sequences and random shapes: Munsinger \& Kessen, 1964; for a recent review on the inverted U-curve 
in preference for music, see Chmiel \& Schubert, 2017). However, other studies reported a positive linear (e.g., for snowflakes: Adkins \& Norman, 2016; for texture patterns: Friedenberg \& Liby, 2016), or even a non-inverted U-shaped relationship (e.g., for solid objects: Adkins \& Norman, 2016; Phillips, Norman, \& Beers, 2010) between complexity and aesthetic appreciation.

The contradictory findings seem to result from several theoretical and empirical difficulties (Nadal et al., 2010). Not only do studies differ enormously in the type, number and ecological validity of the stimuli they used (Marin \& Leder, 2013), but also the way in which complexity was defined, measured, and manipulated varied between studies (Nadal et al., 2010). Additionally, the effects of complexity on aesthetic appreciation might be subject to individual differences (e.g., Aitken, 1974; Güçlütürk et al., 2016; Jacobsen \& Höfel, 2002; Tinio \& Leder, 2009).

Objective and subjective complexity. One important distinction between different types and operationalizations of complexity is the distinction between subjective and objective complexity. Objective complexity refers to the amount or degree of complexity that is physically present in a certain stimulus. This is opposed to subjective complexity, which entails the subjects' perception of the complexity of the stimulus in question. Objective measures of complexity are computed based on the properties of the stimulus itself. Whereas some objective measures are based on statistical image properties, image compression techniques, or edge detection algorithms, others are based on more directly visible stimulus dimensions (for an overview of definitions and examples of studies using them, see Table 1).

Objective complexity measures. Commonly used examples of statistical image properties related to complexity are the measures of self-similarity, complexity, and anisotropy based on the Pyramid of Histograms of Orientation Gradients (PHOG) as well as the measures of Fourier slope and fractal dimension (e.g., Braun, Amirshahi, Denzler, \& Redies, 2013; Mather, 2014). Self-similarity indicates how similar the image as a whole is to its parts (Lyssenko, Redies, \& Hayn-Leichsenring, 2016). It is closely related to scale invariance and fractal dimension, and earlier studies have found museum paintings to be highly self-similar (e.g., Redies, Amirshahi, Koch, \& Denzler, 2012). HOG-based complexity is defined as the mean magnitude of changes in luminance or color in an image. The higher the value of this measure, the more objectively complex the image is (Redies et al., 2012). Anisotropy measures the difference in magnitude of changes in luminance or color across orientations in an image (Braun et al., 2013). Low anisotropy indicates that the strength of the changes is similar across orientations, whereas high anisotropy indicates that some 
orientations are more prominent than others in the image. In previous research, museum paintings and graphic artworks were characterized by a low degree of anisotropy (e.g., Redies et al., 2012).

Fourier slope is an indicator of the strength of low spatial frequencies (representing coarse detail) relative to high spatial frequencies (representing fine detail) in the image (Redies, Brachmann, \& Hayn-Leichsenring, 2015). A slope value of -2 indicates that the image has fractal-like, scale-invariant properties, which means that the relative strength of low and high spatial frequencies stays constant when zooming in or out of the image. In images with a shallower slope (values higher than -2), high spatial frequencies are more prominent than in image with a slope of -2. In images with a steeper slope (values lower than -2), low spatial frequencies are more important (Redies et al., 2014). For images of Western graphic art and natural scenes, the Fourier slope was found to be around -2, indicating scaleinvariant properties (e.g., Redies, Hasenstein, \& Denzler, 2007). Fractal dimension indicates how 'fractal' or self-similar an image is (Hagerhall, Purcell, \& Taylor, 2004). Fractals are shapes that show the same structures or patterns when zooming in or out of the image (Hagerhall et al., 2004). For two-dimensional images, the fractal dimension values are between 1 and 2, with values closer to 2 indicating more complex and intricate images (Mureika \& Taylor, 2013). In previous research, humans preferred intermediate values for the fractal dimension, ranging from 1.3-1.5, although individual differences exist: Different subgroups of participants show an inverted-U, a positive linear, or a negative linear relationship between preference and fractal dimension (Spehar, Clifford, Newell, \& Taylor, 2003; Spehar, Walker, \& Taylor, 2016; Street, Forsythe, Reilly, Taylor, \& Helmy, 2016; Taylor, Spehar, Van Donkelaar, \& Hagerhall, 2011).

Although the relations between the different statistical image properties seem to depend on the type of images analyzed (C. Redies, personal communication, July 2, 2016), earlier research consistently found a relatively high correlation between HOG complexity and fractal dimension (e.g., $r=.82, p<.001$ in Braun et al., 2013). The other correlations seemed more variable (see Table 6 in Braun et al., 2013). Fourier slope and HOG complexity are somewhat related because a more shallow Fourier slope indicates more high frequencies (representing fine detail) in the image, which can make the image more complex. Anisotropy does only relate to complexity in some cases, for example in the most complex and selfsimilar natural images (which have low anisotropy; C. Redies, personal communication, July 2, 2016). 
Other objective measures for complexity are making use of image compression techniques (for a rationale, see Machado et al., 2015), including amongst others GIF (Graphics Interchange Format; e.g., Forsythe, Nadal, Sheehy, Cela-Conde, \& Sawey, 2011; Friedenberg \& Liby, 2016; Marin \& Leder, 2013) and JPEG (Joint Photographic Expert Group; e.g., Chikhman, Bondarko, Danilova, Goluzina, \& Shelepin, 2012; Marin \& Leder, 2013). Another alternative method to calculate objective measures for complexity relies on edge detection algorithms, for instance, perimeter detection and Canny edge detection (Forsythe, Mulhern, \& Sawey, 2008; for a rationale, see Machado et al., 2015).

Objective complexity measures based on more directly visible characteristics of the stimulus include different measures of the number and variety of elements or colors in the stimulus (e.g., number of individual elements; Tinio \& Leder, 2009; number of independent turns in polygonal shapes; Munsinger \& Kessen, 1964).

\begin{tabular}{|c|c|c|}
\hline Name of measure & Definition of measure & Example studies \\
\hline \multicolumn{3}{|c|}{ Statistical image properties } \\
\hline \multirow[t]{10}{*}{ PHOG self-similarity } & the median similarity value & Braun et al. (2013); \\
\hline & between the Histogram of & Lyssenko et al. (2016); \\
\hline & Oriented Gradients (HOG) & Redies et al. (2012); \\
\hline & features for subsections of an & Redies et al. (2015) \\
\hline & image and the HOG feature of a & \\
\hline & larger section of the image (or the & \\
\hline & complete image); indicates how & \\
\hline & similar the image as a whole is to & \\
\hline & its parts; method explained in & \\
\hline & Braun et al. (2013) & \\
\hline \multirow[t]{4}{*}{ HOG complexity } & the mean magnitude of changes & Braun et al. (2013); \\
\hline & in luminance or color in an & Lyssenko et al. (2016); \\
\hline & image; method explained in & Redies et al. (2012); \\
\hline & Braun et al. (2013) & Redies et al. (2015) \\
\hline \multirow[t]{5}{*}{ PHOG anisotropy } & the difference in magnitude of & Braun et al. (2013); \\
\hline & changes in luminance or color & Lyssenko et al. (2016); \\
\hline & across orientations in an image; & Redies et al. (2012); \\
\hline & method explained in Braun et al. & Redies et al. (2015) \\
\hline & $(2013)$ & \\
\hline
\end{tabular}




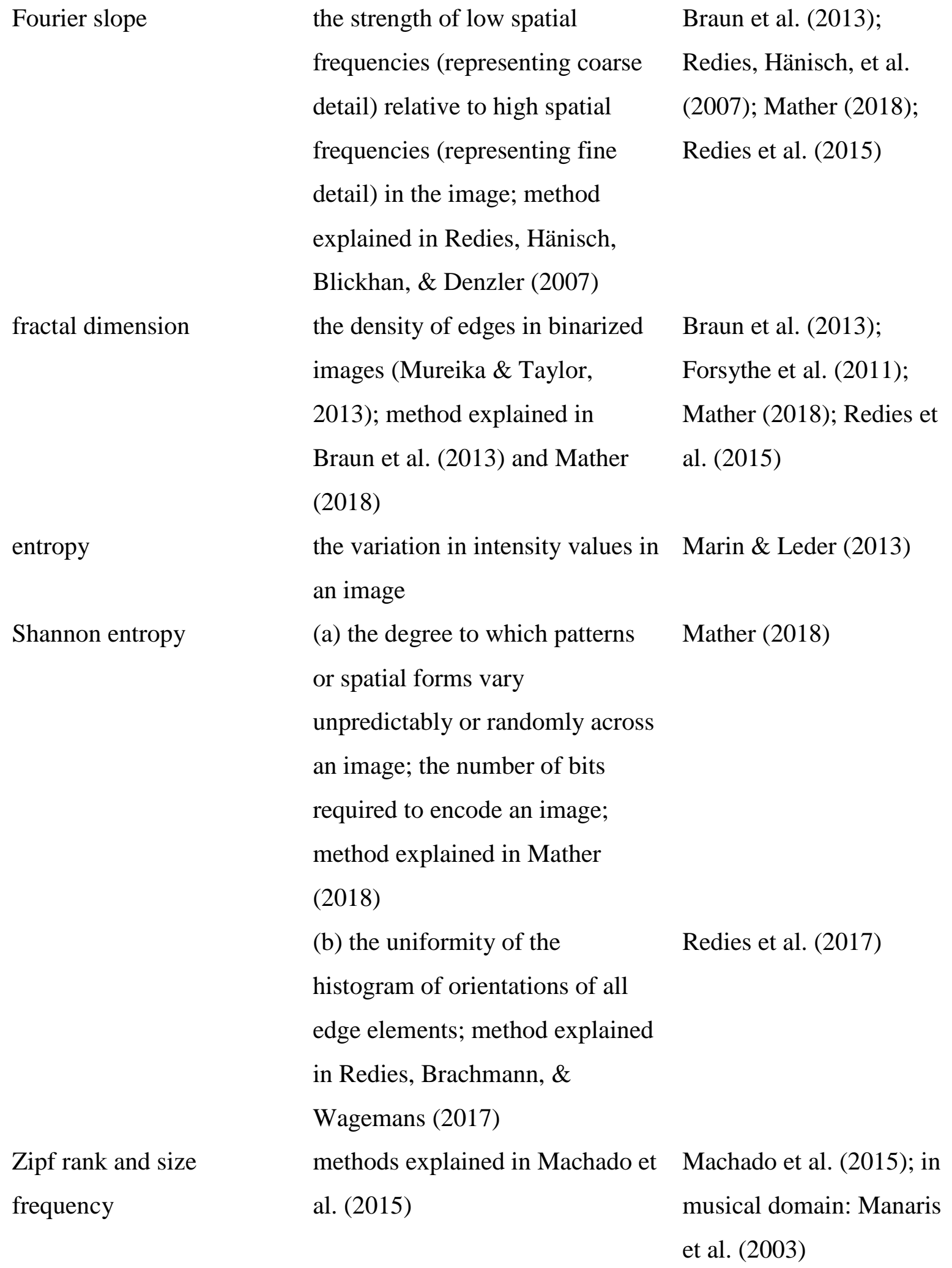

\begin{tabular}{ll}
\hline Image compression & file length of the compressed file \\
techniques & (or reduction in file length \\
& compared to original), using, for \\
& example:
\end{tabular}


(a) Joint Photographic Expert Chikhman et al. (2012);

Group (JPEG) compression, a Donderi (2006b);

method of lossy (i.e., irreversible) Forsythe et al. (2008,

compression;

2011); Gartus \& Leder

(2017); Machado \&

Cardoso (1998); Marin \&

Leder (2013)

(b) Graphics Interchange Format

Forsythe et al. (2008,

(GIF) compression, a method of

2011); Friedenberg \&

lossless (i.e., reversible)

Liby (2016); Gartus \&

compression;

Leder (2017); Marin \&

Leder (2013); Palumbo,

Ogden, Makin, \&

Bertamini (2014)

(c) zip (lossless) compression; Donderi (2006b)

(d) Portable Network Graphics Gartus \& Leder (2017);

(PNG; lossless) compression; $\quad$ Marin \& Leder (2013)

(e) Tagged Image File Format $\quad$ Gartus \& Leder (2017);

(TIFF; lossless) compression Marin \& Leder (2013)

(f) fractal (lossy) image Machado \& Cardoso

compression; method explained (1998); Machado et al.

in Fisher (1995) (2015)

Edge detection algorithms the changes in intensity at the

edges of an image, using for

example:

(a) perimeter detection;

Forsythe et al. (2008, 2011); Gartus \& Leder (2017); Marin \& Leder (2013)

(b) Canny edge detection; $\quad$ Forsythe et al. (2008);

Gartus \& Leder (2017);

Marin \& Leder (2013) 


$\begin{array}{ll}\text { (c) Root Mean Square (RMS) } & \text { Cavalcante et al. (2011); } \\ \text { contrast; method explained in } & \text { Gartus \& Leder (2017); } \\ \text { Cavalcante et al. (2011); } & \text { Marin \& Leder (2013) } \\ \text { (d) phase congruency; method } & \text { Gartus \& Leder (2017); } \\ \text { explained in Kovesi (2003) } & \text { Marin \& Leder (2013) } \\ \text { (e) Sobel edge detection } & \text { Machado et al. (2015) }\end{array}$

\section{Directly visible characteristics}

number of individual elements

Tinio \& Leder (2009)

number of independent turns in polygonal shapes

Munsinger \& Kessen

number of corners, crossing lines, lines, and turns

Chikhman et al. (2012)

Table 1. Objective measures of complexity.

Subjective complexity measures. Measures of subjective complexity take the observer into account, but vary in how much importance they give to individual differences (i.e., averaging over participants or using the separate scores of each individual participant). Examples of how subjective complexity can be measured include two-alternative forcedchoice (2AFC) tasks (e.g., Chipman \& Mendelson, 1979) and rating scales (e.g., Marin \& Leder, 2013).

\section{Aspects of objective complexity determining subjective complexity. Several} researchers have tried to determine the physical and statistical (i.e., objective) aspects of the stimulus that help to predict subjective complexity (e.g., Attneave, 1957; Corchs, Ciocca, Bricolo, \& Gasparini, 2016). In previous studies, statistical image properties like selfsimilarity and HOG complexity showed strong positive correlations with subjective ratings of complexity (e.g., $r=.56$ and $r=.68, p$ s $<.001$, respectively, in Lyssenko et al., 2016). Anisotropy showed a negative correlation with subjective complexity $(r=-.39, p<.001$ in Lyssenko et al., 2016). For patterns varying in fractal scaling properties, perceived complexity increased almost linearly with fractal dimension within each image type (Spehar et al., 2016). Also the objective complexity measures based on JPEG and GIF compression techniques, as well as those measures based on perimeter detection and Canny edge detection, were found to correlate positively with subjective judgments of complexity (Forsythe, Mulhern, \& Sawey, 2008; Forsythe et al., 2011; Palumbo, Ogden, Makin, \& Bertamini, 2014).

Subjective complexity is not reducible to aspects of objective complexity, however (Arnheim, 1954/2004; Attneave, 1957). For example, individual differences exist in which 
aspects of objective complexity determine an individual's perceived complexity and to what extent (cf. "Individual differences in the perception of order and complexity"). Furthermore, the importance of different aspects of objective complexity for subjective complexity may vary depending on the type of stimuli selected (e.g., Chikhman et al., 2012: Marin \& Leder, 2013) or on the definition of complexity given to the participants (e.g., Oliva, Mack, Shrestha, \& Peeper, 2004).

Other researchers have specified a number of dimensions to categorize the different objective complexity factors influencing subjective complexity (e.g., Berlyne et al., 1968; Nadal et al., 2010). According to Berlyne (1960), the subjective complexity of a stimulus is positively related to the number of distinguishable elements and the dissimilarity between those elements. Additionally, he postulated a negative relation between perceived complexity and the degree to which several elements are responded to as a unit (Berlyne, 1960). A factor analysis conducted by Berlyne, Ogilvie, and Parham (1968) indicated two main factors determining subjective complexity: (a) the number of independently selected component elements, which they called an 'information content' dimension; and (b) a dimension they called 'unitariness vs. articulation into easily recognizable parts'. With this concept, they refer to the degree in which the elements are grouped together as indistinguishable units in a cluster relative to a form of hierarchical organization in which the elements retain an important role as natural parts of a larger whole (for more discussion of different kinds of grouping, see Wagemans, 2018).

In line with this, Chipman (1977) distinguished between quantitative and structural variables influencing perceived complexity. She argued that where the quantitative variables set the upper limit for the amount of perceived complexity, the detection of psychologically relevant organization (i.e., the structural variables) can reduce subjective complexity. Nadal et al. (2010) later differentiated between three different forms of visual complexity that influenced people's perception of complexity: subjective complexity related to (a) the amount and variety of elements, (b) the ways those elements are organized, and (c) asymmetry ${ }^{1}$. They also reported preliminary evidence for differential relationships between these three factors determining subjective complexity and aesthetic appreciation. Whereas the amount and variety of elements had a positive linear relationship with aesthetic appreciation, a descending U-shaped relation was found for complexity in the ways the elements in a stimulus are

\footnotetext{
${ }^{1}$ Although the work of Nadal et al. (2010) is an important theoretical contribution for distinguishing between and structuring of the different uses of the term complexity in the existing literature, we will reinterpret these different types of complexity below in terms of order and complexity.
} 
organized. Furthermore, asymmetry showed an inverted U-shaped relationship with aesthetic appreciation.

Complexity as a multidimensional concept. Besides Berlyne et al. (1968), Chipman (1977), and Nadal et al. (2010), other authors have also noted that visual complexity is a multidimensional concept (e.g., Kreitler, Zigler, \& Kreitler, 1974; Rump, 1968). Rump (1968) reported that individuals' preferences for different aspects of objective complexity did not correlate with each other. This means that individuals' preference for a specific type of objective complexity did not reflect whether they also preferred other types of objective complexity. Kreitler et al. (1974) did find some correlations between the preferences for different complexity dimensions they examined, but the correlations were very low. However, most research on complexity and aesthetic appreciation has used complexity as a unidimensional concept, not distinguishing between different aspects of complexity (Nadal, 2007). As mentioned earlier, various operationalizations of complexity have been used, which may be one of the reasons why differential relationships between complexity and aesthetic appreciation have been found (Nadal, 2007). As Nadal et al. (2010) found preliminary support for differential relationships between the types of complexity they distinguished and aesthetic appreciation, it appears that acknowledging the multidimensionality of complexity may be a fruitful approach in the search for more consistent relationships between complexity and aesthetic appreciation.

\section{Subjective complexity resulting from objective complexity and order. The} literature reviewed above (e.g., Berlyne et al., 1968; Chipman, 1977; Nadal et al., 2010) defined subjective complexity as dependent on aspects related to the quantity and variety of elements in a stimulus as well as aspects related to the structure and organization in the stimulus. We agree with the authors mentioned above that subjective complexity may be defined based on these different dimensions. However, we will define objective complexity as only containing those aspects related to the quantity and variety of information in a stimulus, very similar to the first dimension mentioned by Berlyne et al. (1968) and Nadal et al. (2010). Objective order will be used to refer to aspects related to the structure and organization of the information in the stimulus (cf. the second dimension of Berlyne et al., 1968, and the second and third dimension of Nadal et al., 2010).

\section{Order and Aesthetic Appreciation}

Besides complexity, the order or organization present in a stimulus is also generally accepted to influence aesthetic appreciation. Although Nadal et al. (2010) described how the elements in the stimulus are organized and the symmetry present in the stimulus as aspects of 
complexity, we will regard them as aspects of order instead. We thus define (stimulus) order as those aspects related to the structure and organization of information (in the stimulus).
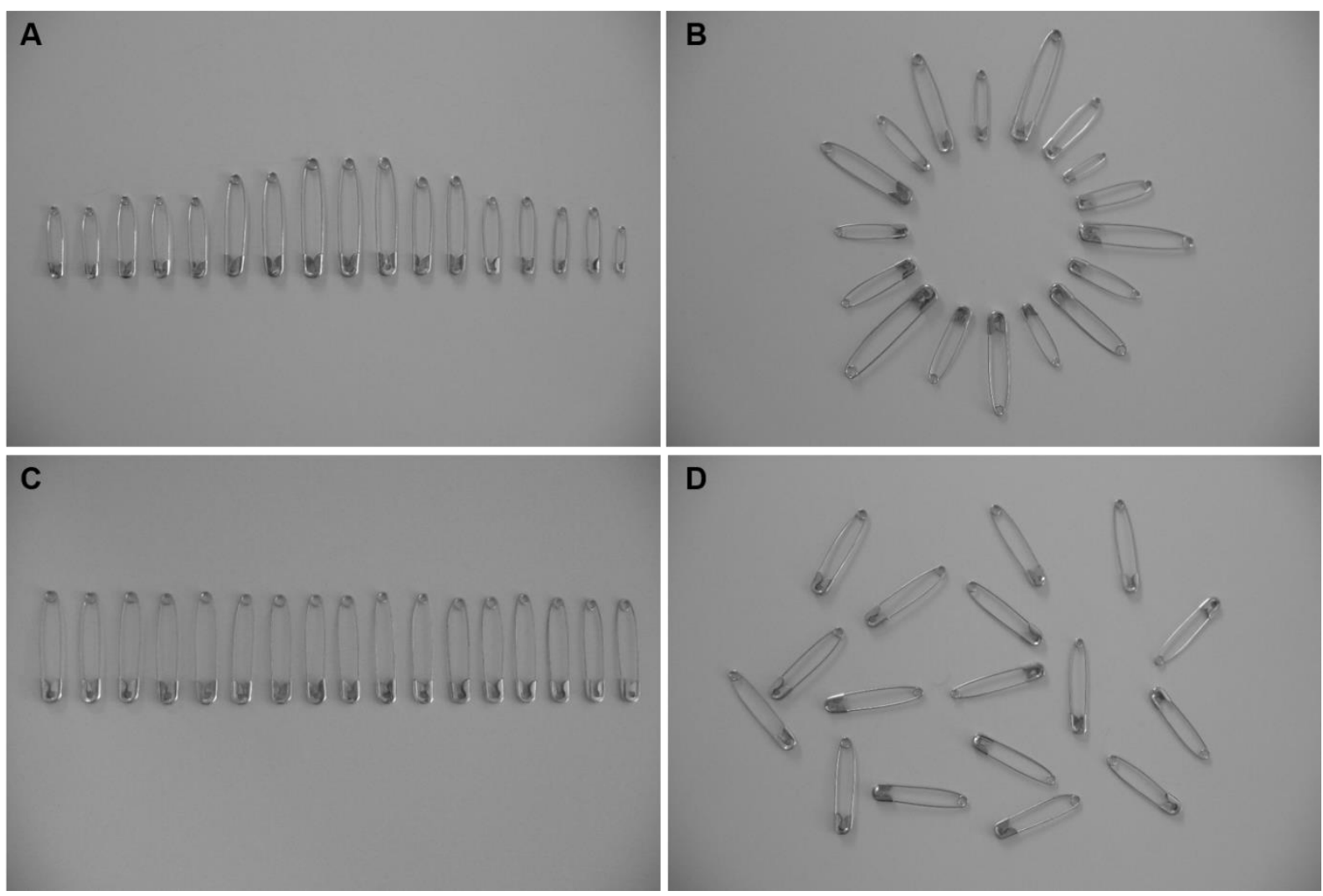

Figure 1. Order and complexity on different stimulus dimensions in images of neatly organized compositions. Figure licensed under CC BY 4.0 by the authors. Retrieved from https://doi.org/10.6084/m9.figshare.6144233.

Simplicity versus order. It is important to clarify that we distinguish order from simplicity (and complexity from disorder). In what follows, simplicity is defined as opposite to complexity, indicating the quantity and variety of information content in a stimulus (varying from low to high). In contrast, order refers to how the elements in the stimulus are organized or structured, and how well this is the case, without taking into account the number or variety of elements present in the stimulus. Of course, the degree of order or disorder that can be present on a certain stimulus dimension will depend on the degree of complexity present on that dimension, in the sense that there is more room for an effect of order versus disorder when the number or variety of elements is larger. A stimulus that is complex on a certain stimulus dimension (e.g., showing a lot of variety in the size of its elements; see Figures 1A and 1B) can also be very ordered, both on the same dimension (e.g., a systematic gradient in sizes can be presented; see Figure 1A) and/or on other stimulus dimensions (e.g., together the elements can form an ordered configuration such as a circle; see Figure 1A). On 
the other hand, a stimulus that is very simple on a certain stimulus dimension (e.g., all elements in the stimulus have the same size; see Figure 1C) usually cannot be very disordered on the same dimension, but the stimulus can be very disordered on other stimulus dimensions (e.g., different orientations of the elements in the stimulus; see Figure 1D). So, there is a lot of room for interactions between order and complexity to take place, but it is better to keep the concepts distinct at the level of the definitions.

As was the case with complexity, different conceptualizations of order have been used in the literature. However, less systematic research appears to have been done about the different conceptualizations and operationalizations of order than those of complexity (for some objective measures and examples of their use, see Table 2). Furthermore, whereas the distinction between objective and subjective order would make sense, it has not typically been used in the literature. Objective order refers to the structure and organization that is physically present in a certain stimulus (e.g., symmetry, iteration, alignment). This is opposed to subjective order, which entails the subjects' perception of the order of the stimulus in question. Lyssenko et al. (2016) found that participants' evaluation of structure in a set of abstract artworks correlated negatively with objective, statistical image properties like PHOG self-similarity $(r=-.24 ; \mathrm{p}<0.001)$ and HOG complexity $(r=-.29 ; \mathrm{p}<0.001)$, and negatively with anisotropy $(r=.22 ; \mathrm{p}<0.001)$. Marković and Radonjić (2008) investigated correlations between implicit (i.e., subjective) and explicit (i.e., objective) features of paintings and found judgments concerning the implicit feature of regularity (e.g., arranged, precise, regular) to correlate positively with judgments concerning explicit features of form (e.g., precise, neat, salient form) and space (e.g., voluminosity, spatial depth, oval contours).

One aspect of order that did get considerable attention in the empirical research literature on aesthetic appreciation is symmetry. One of the reasons that other aspects of order have remained understudied may be that those aspects seem less straightforward to measure in a purely objective way than symmetry or aspects of complexity. Arnheim (1954/2004, p. 19), for example, indicated that "[e]xcept for the most regular shapes, no known method of rational calculation can replace the eye's intuitive sense of balance". Furthermore, some aspects of order have been studied under the label of complexity (which has added to the confusion in the literature). 


\begin{tabular}{lll}
\hline \multicolumn{1}{c}{ Name of measure } & \multicolumn{1}{c}{ Definition of measure } & \multicolumn{1}{c}{ Example studies } \\
\hline $\begin{array}{l}\text { Symmetry } \\
\text { mirror symmetry }\end{array}$ & $\begin{array}{l}\text { similarity of pixel values on both } \\
\text { sides of a reflection axis; method }\end{array}$ & Gartus \& Leder (2017); \\
& explained in Hübner \& Fillinger & (2016) \\
& $(2016)$ & \\
\hline parallelism & similarity of orientation of & Redies et al. (2017) \\
& different edges in the image; & \\
& method explained in Redies et al. & \\
& (2017) & \\
\hline similarity of number of black & Gartus \& Leder (2017); \\
pixels in different subsections of & Hübner \& Fillinger \\
& a binarized image; method & (2016) \\
& explained in Hübner \& Fillinger & \\
& (2016) & \\
\hline
\end{tabular}

\section{Perceptual balance}

objective overall balance score

deviation of the center of "mass" (DCM) the average of eight measures of symmetry; method explained in Wilson \& Chatterjee (2005) the Euclidian distance of the twodimensional center of "mass" to the picture's geometrical center; method explained in Hübner \& Fillinger (2016)

rule of thirds (ROT) metric saliency map-based measure indicating to which extent the rule of thirds was present in an image; method explained in Amirshahi et al. (2014)
Gartus \& Leder (2017); Hübner \& Fillinger (2016); Wilson \& Chatterjee (2005)

Gartus \& Leder (2017); Hübner \& Fillinger (2016)

Amirshahi et al. (2014)

Table 2. Objective measures of order.

Order as a multidimensional concept. Like complexity, order can be viewed as a multidimensional concept. Different types of order exist (e.g., similarity grouping, symmetry, 
alternation/iteration, systematic alteration/gradient, etc.) and order can occur with respect to different dimensions (e.g., orientation, color, size, shape, spatial composition/configuration, etc.). Below some important components of order and their relation to aesthetic appreciation will be highlighted.

Perceptual grouping principles. Gestalt psychologists formulated different grouping laws (Arnheim, 1954/2004; for a review, see Wagemans et al., 2012) including the principles of similarity (e.g., in orientation, color, size, shape), proximity (i.e., similar spatial location), common fate (i.e., similar direction or speed), symmetry and parallelism, continuity, and closure. The most general Gestalt law is the law of Prägnanz, which states that objects within the perceptual field (and the perceptual field in itself) will be organized in the simplest and most encompassing way possible given the current conditions (Wagemans et al., 2012). In his book "Art and Visual Perception", Arnheim (1954/2004) described the close relationship between the Gestalt principles and the arts: "at no time could a work of art have been made or understood by a mind unable to conceive the integrated structure of a whole" (p. 5) and "All works of art have to be looked at 'from above,' that is, with a primary grasp of the total organization. At the same time, however, relations among the parts often play an important compositional role" (p. 88).

Some authors hypothesized that aesthetic appreciation is generated from being able to group elements together and to detect the properties that bring order and unity to them (Post et al., 2016; Ramachandran \& Hirstein, 1999). Also Koffka already described a link between Gestalt psychology and aesthetic appreciation (Koffka, 1940; recently revisited by Spehar \& van Tonder, 2017). However, somewhat surprisingly perhaps, not much empirical research has systematically investigated the specific role of the grouping principles in relation to aesthetic appreciation.

Symmetry. One grouping principle for which evidence does exist, is symmetry, a higher-order regularity to which the human visual system is highly sensitive (for reviews, see Bertamini, Silvanto, Norcia, Makin, \& Wagemans, 2018; Wagemans, 1997). In the study of Jacobsen and Höfel (2002), symmetry was found to be the most important factor in the aesthetic appreciation of graphic patterns. Most studies argue that people prefer symmetry above non-symmetry (e.g., Cárdenas \& Harris, 2006; Eisenman \& Rappaport, 1967; Jacobsen et al., 2006; Munsinger \& Kessen, 1964; Westphal-Fitch, Huber, Gómez, \& Fitch, 2012). Cárdenas and Harris (2006) showed that participants preferred symmetrical designs above asymmetrical designs. Westphal-Fitch et al. (2012) used the method of production and found that people spontaneously produced highly ordered, often symmetrical, visual patterns, 
without being instructed to do so. However, some other investigations point to a preference for slight asymmetry, for example when comparing Mondrian's paintings to symmetrical alternatives (Swami \& Furnham, 2012). A recent study found that symmetrical patterns were preferred over asymmetrical ones in both implicit and explicit evaluative tasks (Weichselbaum et al., 2018). Explicit beauty ratings for asymmetrical patterns increased with art expertise, however.

Perceptual balance and the rule of thirds. Symmetry can be seen as the simplest type of visual or perceptual balance (Arnheim, 1954/2004; Wilson \& Chatterjee, 2005). Besides for the importance of symmetry, there is evidence for the importance of dynamic balance in determining aesthetic appreciation. Dynamic balance arises from a stimulus in which the visual forces of the different elements compensate each other (Arnheim, 1954/2004; Wilson $\&$ Chatterjee, 2005). An objective measure of dynamic balance accounted for considerable amounts of the variance in preference ratings for images with circles, hexagons, and squares ( $R^{2}$ between .44 and .78; Wilson \& Chatterjee, 2005). Also Hübner and Fillinger (2016) found perceptual balance to be a predictor for ratings of aesthetic appreciation. Locher and colleagues (Locher, Cornelis, Wagemans, \& Stappers, 2001; Locher, Stappers, \& Overbeeke, 1998) asked participants to create visual designs themselves. For most participants, the center of the design was very near to the geometric center of the display field, indicating perceptual balance.

One specific type of visual balance can emerge when an image follows the rule of thirds. The rule of thirds (ROT) is a well-known rule for composition in two-dimensional visual art like paintings and photographs, which indicates that the focus point of an image should be located along one of the third lines, or on one of the four intersections of the third lines, to be perceived as aesthetically pleasing (Amirshahi, Hayn-Leichsenring, Denzler, \& Redies, 2014). When cropping photographs, the saliency center-of-mass was closer to the geometrical center for details selected than for details avoided by participants (Abeln et al., 2016). For a large set of photographs, however, aesthetic ratings correlated only weakly with subjective ROT and not at all with objective ROT measures (Amirshahi et al., 2014).

\section{Conceptual Dimensions of Order and Complexity}

Order and complexity can also occur on conceptual or semantic dimensions (i.e., dimensions relating to concepts or ideas or to meaning). Birkhoff (1933) distinguished formal and connotative elements of order. Formal elements of order (e.g., repetition, similarity, contrast, equality, symmetry, balance, and sequence) involve a reference to a simple physical property of the aesthetic stimulus. Connotative elements of order involve all properties of the 
stimulus that are not of this simple formal type. Nicki and Moss (1975) distinguished between perceptual and conceptual complexity, the first being related to the number of stimulus elements and the degree of irregularity in their arrangement and the second factor being related to the cognitive labels or associations evoked by the stimulus.

The fact that most studies in aesthetics have focused either on form (i.e., perceptual dimensions) or on content (i.e., conceptual or semantic dimensions) was mentioned by Berlyne (1960) as one of the problems with the aesthetics research of his time. Phillips et al. (2010) suggested that the interaction of 'denotative' and 'connotative' properties of artworks could drive the contrasting findings in the aesthetics literature in the sense that the connotations given to an artwork can be very peculiar for each observer, possibly leading to large individual differences. Additionally, although visual complexity correlated negatively with perceived presentation duration for stimuli containing semantic content (Cardaci, Di Gesù, Petrou, \& Tabacchi, 2009), visual complexity did not relate to perceived duration of images lacking semantic content (Palumbo et al., 2014).

Some studies found conceptual or semantic factors to be the most important ones in determining aesthetic appreciation (e.g., Martindale, Moore, \& Borkum, 1990). In addition, some studies found evidence for a preference for less conceptual ambiguity. Stephens and Hoffman (2016) reported that textures with fewer descriptions (i.e., fewer possible conceptual organizations of the stimulus content) were liked better. Taylor and Franklin (2012) observed the same for colors: Colors associated with fewer objects were liked better than colors associated with many objects.

Recent work emphasized the importance of insight (i.e., Aha experience) and how it reduced ambiguity (i.e., by increasing conceptual order) in increasing aesthetic appreciation (e.g., Muth \& Carbon, 2013). Furthermore, also the anticipation of insight already led to an increase in aesthetic appreciation (e.g., Muth, Raab, \& Carbon, 2015). Although this (anticipated) reduction of semantic instability was found to increase aesthetic appreciation in general, further research will be needed to specify how different types of semantic instability relate to aesthetic appreciation under different circumstances (e.g., individual and contextual differences; Muth \& Carbon, 2016).

Whereas the results of Munsinger and Kessen (1964) supported the inverted U-shaped function between variability (i.e., complexity) and aesthetic appreciation, they found unexpectedly high preference for extremely simple and extremely complex figures. The preferences for extremely complex figures could be accounted for by effects of meaningfulness: The extremely complex figures were judged much more meaningful than the 
figures with intermediate complexity. In sum, also conceptual or semantic aspects of order and complexity seem to influence aesthetic appreciation.

\section{Aesthetic Appreciation and the Balance Between Order and Complexity}

Both order and complexity are thus important in determining aesthetic appreciation. One additional reason for the contrasting findings in both fields of study could be that effects order and complexity are intertwined, and that it is the balance between the two that influences aesthetic appreciation (see Figure 2).

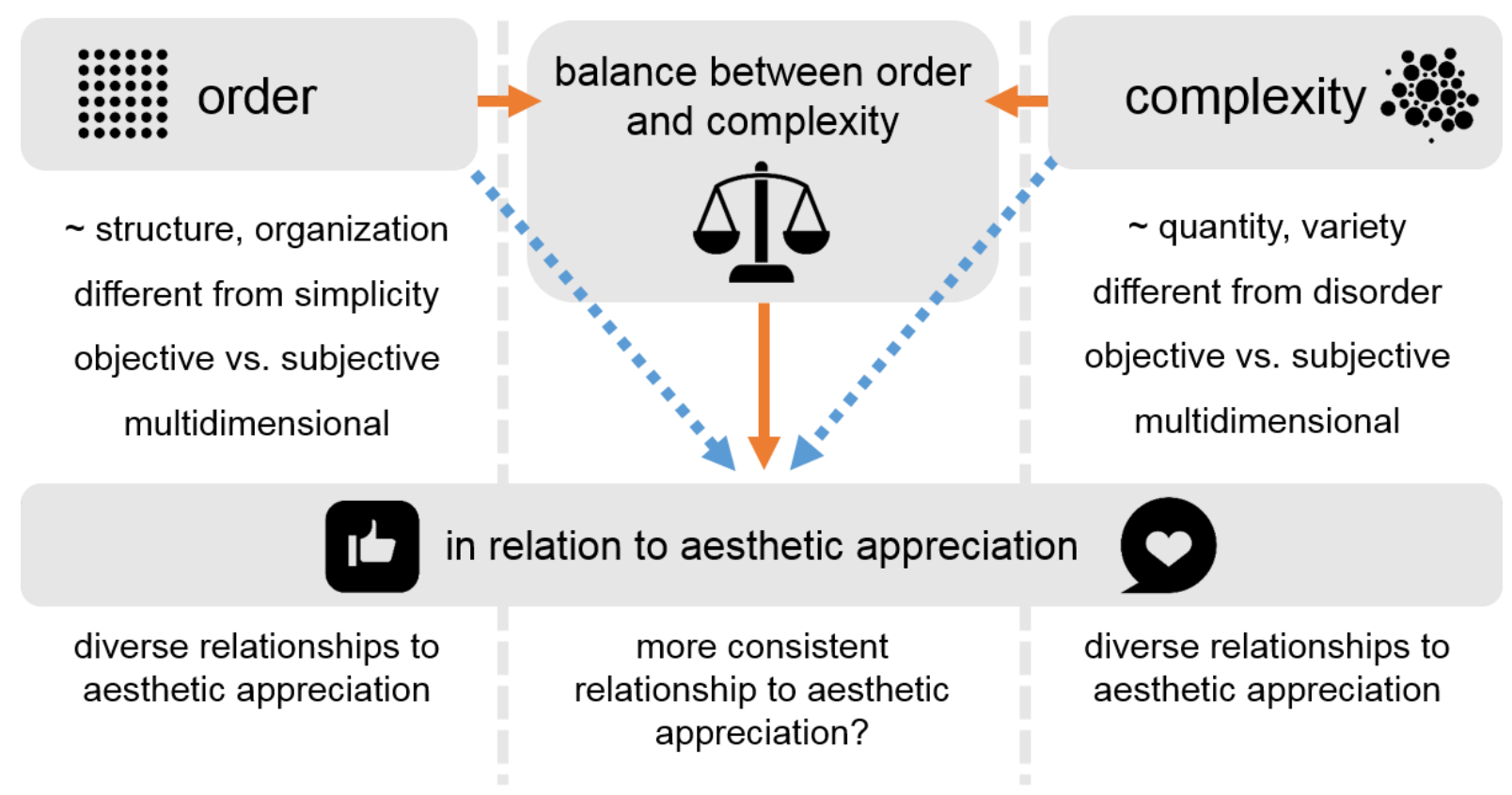

Figure 2. Order, complexity, and their interplay in relation to aesthetic appreciation. The blue dotted and orange continuous arrows indicate the possibility of order and complexity as independent or interacting factors influencing aesthetic appreciation, respectively. Figure licensed under CC BY 4.0 by the authors. Retrieved from https://doi.org/10.6084/m9.figshare.6144383.

Early ideas. Throughout history, the importance of an appropriate balance between order (also referred to as unity, uniformity, synthesis, harmony, lawfulness, and organization) and complexity (also variety, diversity, or multiplicity are used) in explaining aesthetic appreciation has been suggested by many different philosophers, including Philo, Plotinus, Descartes, Hutcheson, Baumgarten and Moses Mendelssohn (Gilbert \& Kuhn, 1953/1972; Rist, 1967). By introducing an aesthetics "from below", Fechner's (1876) work represented a transformation from more deductive and theoretical to more inductive and experimental

\footnotetext{
${ }^{2}$ This is used in contrast to the philosophical aesthetics "from above" and not used in contrast to the earlier mentioned "from above" in the section about perceptual grouping principles.
} 
methods in the field of aesthetics (Cupchik, 1986). With his formal principle of unified connection of the manifold (Gilbert \& Kuhn, 1953/1972), Fechner proposed that stimuli that are experienced as pleasing must provide an adequate balance between order (i.e., 'unified connection') and complexity (i.e., 'the manifold'; Cupchik, 1986). Furthermore, he argued that people will tolerate a moderate level of arousal more frequently and for a longer time than a very low or very high level, as this would cause under- or overstimulation, respectively (his 'principle of the aesthetic middle'; Cupchik, 1986).

Based on Wundt's (1874) inverted-U curve showing that pleasantness is perceived as highest for medium stimulus intensities, Berlyne proposed a similar association between pleasure and arousal potential: "moderate arousal potential will be maximally rewarding" (Berlyne, 1960, p. 201). However, this optimal level of arousal is supposed to depend on a large number of different factors, including collative (related to the viewer's expectations), psychophysical (related to the sensory dimensions of the stimulus), and ecological variables (related to the meaningfulness and associations to environmental objects; Palmer et al., 2013). When applying his arousal theory to aesthetic appreciation, also Berlyne (1960) discusses the principle of unity in diversity. He relates diversity to two factors that constitute complexity (i.e., heterogeneity and numerosity of elements), but argues that diversity can also entail novelty, ambiguity, and surprise. In contrast, the principle of unity is proposed to moderate or diminish arousal levels (Berlyne, 1960).

Clarifying the relation between order and complexity. As long as no clear definition of unity (i.e., order), diversity (i.e., complexity), or their relation (i.e., balance) is given, we cannot really do anything with this theoretical proposal of a balance between order and complexity influencing aesthetic appreciation (Eysenck, 1942). Birkhoff (1933), a mathematician, was the first who tried to define these concepts and their relation in a more exact way (Eysenck, 1942). His theory of aesthetic preference $(M=O / C)$ stated that a measure of aesthetic preference $(\mathrm{M})$ should vary positively with the amount of order $(\mathrm{O})$ and negatively with complexity (C; Boselie \& Leeuwenberg, 1985; Palmer et al., 2013) ${ }^{3}$. Birkhoff specified in detail how he defined order and complexity by identifying different stimulus properties that could be seen as different manifestations of order and complexity for a series of different object classes, including polygons and melodies (Boselie \& Leeuwenberg, 1985).

\footnotetext{
${ }^{3}$ A similar formula has been proposed in the context of a more general theory about the perception of regularity. Indeed, the key formula of Van der Helm and Leeuwenberg's (1996) holographic approach to the goodness or weight $(\mathrm{W})$ of regularity is: $\mathrm{W}=\mathrm{E} / \mathrm{N}$, in which $\mathrm{E}$ is evidence for regularity (i.e., order) and $\mathrm{N}$ the total amount of information (i.e., complexity).
} 
He argued that the elements determining order and complexity should be identified for each class of objects separately (Eysenck, 1942). No convincing empirical evidence was found to support Birkhoff's formula, however (Boselie \& Leeuwenberg, 1985; Palmer et al., 2013).

Eysenck (1942) acknowledged Birkhoff's contributions, but pointed out that subsequent steps to take were (a) to identify the elements that determine order and complexity empirically (instead of via deductive reasoning); and (b) to derive a general formula to represent the relation between order and complexity in an experimental way. Therefore, Eysenck (1941) developed an empirical aesthetic formula to predict the preference of humans for simple polygons (Boselie \& Leeuwenberg, 1985; Nadal, 2007). In Eysenck's measure (M $=\mathrm{O} \times \mathrm{C}$ ) both order and complexity could positively contribute to aesthetic preference, whereas Birkhoff's measure predicted complexity to be negatively correlated with liking. Eysenck predicted that his measure would apply to aesthetic preference in any set of visual stimuli (Nadal, 2007), although he believed that the final formula would inevitably be more complicated than his simple proposal (Eysenck, 1942).

Arnheim postulated an antagonistic but also a complementary relationship between both concepts. More specifically, he stated that although order tends to reduce complexity and complexity tends to reduce order, order and complexity also need each other: "Complexity without order produces confusion. Order without complexity causes boredom.” (Arnheim, 1966, p. 124). Gombrich (1984/1992) later stated: "We must ultimately be able to account for the most basic fact of aesthetic experience, the fact that delight lies somewhere between boredom and confusion." (Gombrich, 1984/1992, p. 9). In later work, Arnheim referred to what he previously called order as orderliness, and describes the balance between orderliness and complexity as order. "A structure can be more or less orderly at any level of complexity. The level of ordered complexity is the level of order" (Arnheim, 1971, p. 51). Arnheim regarded 'order' (i.e., the balance between orderliness and complexity) as a necessary but not a sufficient condition for aesthetic appreciation (Arnheim, 1971).

The balance between order and complexity was nicely demonstrated in a study by Eisenman and Gellens (1968), in which they simultaneously varied symmetry and complexity (in this case, the number of vertices of the figures). Participants showed a strong preference for complex symmetric figures over the other three possible combinations (i.e., simple symmetric, simple asymmetric, and complex asymmetric figures). The balance between order and complexity has also been discussed in many other research fields and application contexts, including acoustics (e.g., Fletcher, 2012), webpage design (e.g., Deng \& Poole, 2012; Post, Nguyen, \& Hekkert, 2017), environmental aesthetics (e.g., Nasar, 1994), fashion 
(e.g., Gray, Schmitt, Strohminger, \& Kassam, 2014), and product design (e.g., Post et al., 2016).

Post et al. (2016) defined the principle of unity-in-variety as "the maximization of both unity and variety, in order to achieve a balance that offers the greatest aesthetic appreciation" (p. 142). They argued that unity is the dominant factor in the relationship between unity and variety, and that unity (i.e., order) facilitates the appreciation of variety (i.e., complexity). They tested this idea of unity and variety being partial opposites while simultaneously contributing to aesthetic appreciation in the field of product design. They found an asymmetrical relationship between unity and variety, in the sense that the appreciation of variety was dependent on the presence of unity, whereas unity can be appreciated independently of variety (Post et al., 2016). From a study on webpage aesthetics, Post et al. (2017) concluded that "both unity and variety independently and positively influence aesthetic appreciation" (p. 48) and that "simultaneously maximizing unity and variety leads to an optimal balance where aesthetic appreciation is highest" (p. 48).

Revisiting the various relationships. Although the principle of balancing order and complexity (i.e., unity in variety) has been regarded as one of the fundamental principles of aesthetics since ancient times, very few empirical studies have investigated the balance between order and complexity in a direct way (Post et al., 2016). As Eysenck (1942) indicated, we need clear definitions of the aspects involved, which are order and complexity, but also their relation, before this idea of balance can be useful in explaining human aesthetic appreciation. Based on the literature reviewed above, we will now present our own, more integrative view on the relation between order and complexity in determining aesthetic appreciation. We follow Arnheim (1966) in that the relationship between order and complexity is both antagonistic and complementary. On the one hand, order and complexity can be seen as partial opposites: Complexity reduces order, order reduces complexity (Arnheim, 1966). On the other hand, we expect order and complexity to complement each other. Whereas order needs complexity to show its structuring and clarifying potential, complexity needs order to be understood and appreciated.

Order and complexity as partial opposites. Although a lot of different types of order exist, we will use the example of similarity here. Similarity is a form of order (i.e., a way in which the information in a stimulus is structured or organized), but it can also be seen as indicating a low level of complexity (i.e., a smaller amount and variety of information: simplicity). For example, noticing that all elements in the stimulus shown in Figures $1 \mathrm{C}$ and 1D have the same size cannot only make this image look less complex than other images, it is 
also a way to perceive the shown elements as a coherent whole. The similar size becomes a form of order or organization. This is one reason why we think order and complexity are interrelated and need to be studied together.
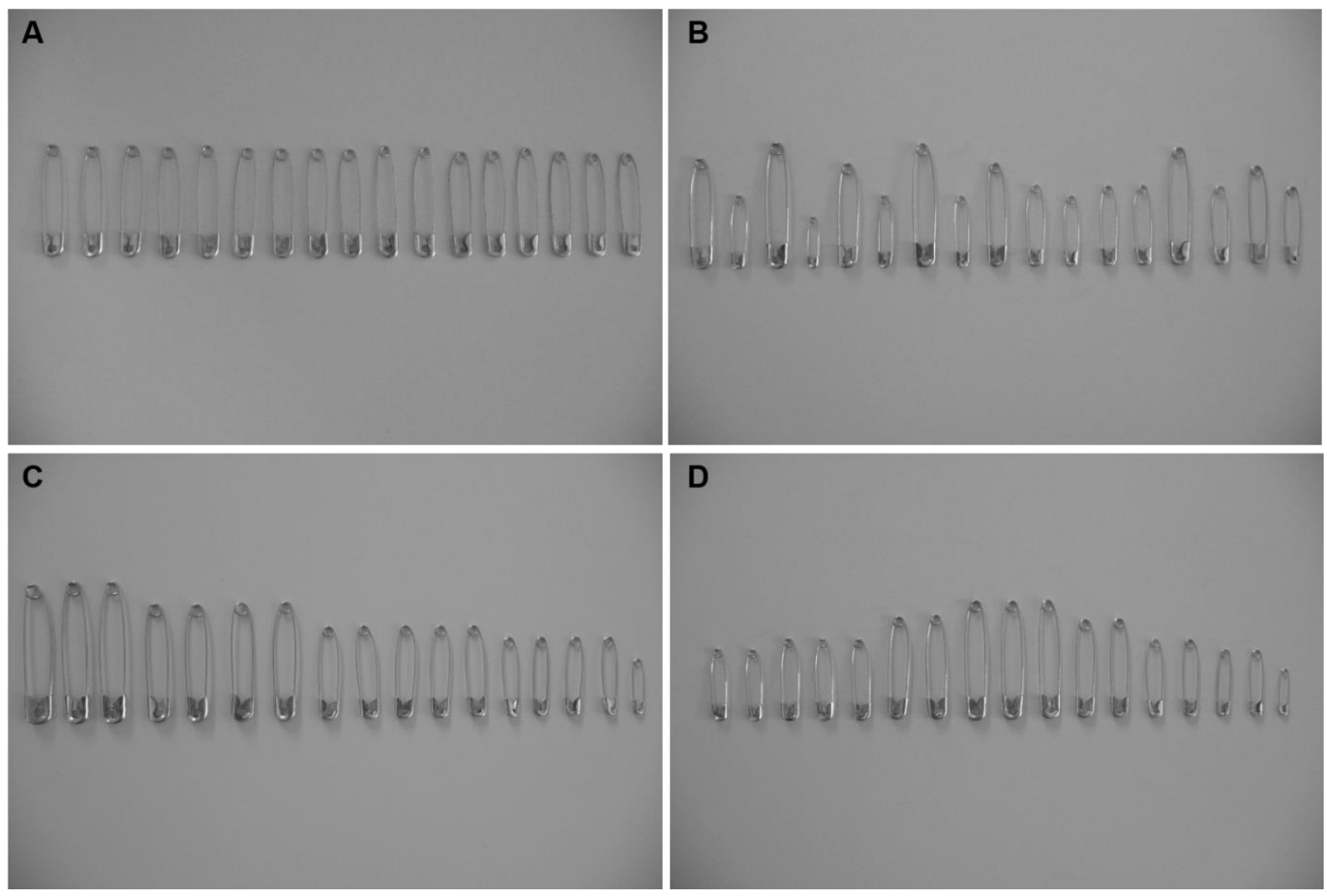

Figure 3. Illustration of order and complexity as partial complements. Order needs complexity to show its possibilities, complexity needs order to be appreciated. Figure licensed under CC BY 4.0 by the authors. Retrieved from https://doi.org/10.6084/m9.figshare.6144380.

Order and complexity as partial complements. A second reason is that order and complexity also need each other. On the one hand, order needs complexity to be able to show its possibilities. With more complexity (i.e., larger number and variety of elements present in the stimulus), more possibilities arise for ordering or not ordering these elements. When complexity is low on a certain dimension, there are fewer possibilities to order the stimulus on that dimension than when complexity is high on that dimension (e.g., Figure 3A versus 3BD). We expect the degree of complexity present in a stimulus to determine the order or disorder that can be present in that stimulus, both quantitatively and qualitatively. That is, compared to stimuli with lower levels of complexity (e.g., Figure 3A), stimuli with higher levels of complexity can show a broader range of quantitatively different (dis)order levels. For instance, Figure 3B is much less ordered than Figures 3C and 3D. Moreover, they can show a 
broader range of qualitatively different orderings, even with similar levels of order. For instance, Figures 3C and 3D are both quite ordered but in very different ways: grouped by size in decreasing order in Figure 3C and in order of increasing versus decreasing size in Figure 3D (giving rise to a more symmetric arrangement). Furthermore, ordered stimuli that lack complexity may be perceived as boring.

On the other hand, complexity also needs order. Stimuli that are highly complex (i.e., contain a large amount and variety of information) can only be 'understood' and aesthetically appreciated when the information is sufficiently structured. Completely unstructured or disordered stimuli may require too much energy or processing capacity and may be perceived as confusing. This is in line with the ideas of Post et al. (2016), who argued that unity (i.e., order) facilitates the appreciation of variety (i.e., complexity).

We summarize our ideas on the balance between order and complexity with the words of Moore (1917, p. 145):

"Real art demands that we put forth a vigorous effort to comprehend a manifold of impressions in a single scheme of thought. When this effort is severe but successful, aesthetic joy is at its very pitch; when only a listless effort is called forth, the aesthetic work is trivial; when the effort demanded exceeds our powers of mental activity, or when there is violent thwarting of the powers called into play, we experience the painful shock of ugliness."

In conclusion, it seems clear that order and complexity interact in how they influence aesthetic appreciation. While on the one hand contrasting each other, order and complexity also depend on each other's presence to optimize appreciation. However, individuals can vary in the amount of order they prefer relative to the amount of complexity that is present. In other words, individuals can vary in their preferred level of balance between order and complexity.

\section{Alternative Accounts of Aesthetic Appreciation}

In our review so far, we have focused on the balance between order and complexity as a fundamental factor for aesthetic appreciation. However, other theories and principles of aesthetic appreciation have been proposed and used in empirical aesthetics too. Here we briefly discuss some of the important theories of aesthetic appreciation and demonstrate how they can be related to the perspective of balancing order and complexity as well. It is our aim to show the complementarity of the different theories regarding their views on how order and complexity relate to aesthetic appreciation rather than to pinpoint which theory should be preferred over the others. 
Processing fluency and aesthetic appreciation. Reber and colleagues (e.g., Reber, Schwarz, \& Winkielman, 2004) proposed processing fluency as a crucial determinant of aesthetic appreciation. In their fluency theory, they state that the more fluently a stimulus is processed, the more the stimulus will be preferred. Although it can explain many different phenomena in the field of experimental aesthetics (cf. Palmer et al., 2013), it would predict a linear decrease in preference with increasing complexity, as increased complexity is expected to require increased processing and complex stimuli would thus be processed less fluently than simpler ones. Several attempts have been made to reconcile preferences for complexity and the framework of processing fluency (e.g., Belke et al., 2015). Recently, Joye, Steg, Ünal, and Pals (2016) found evidence that some highly complex types of stimuli characterized by high internal repetition (e.g., fractals) can be processed fluently despite their visual complexity. More specifically, they asked participants to solve some puzzles while being exposed (or after being exposed) to either high-fractal or low-fractal stimuli. They found that participants solved the puzzles that were presented in combination with the high-fractal stimuli in less time and more accurately than puzzles presented in combination with the lowfractal stimuli. Furthermore, participants perceived the puzzles associated with the highfractal stimuli as easier than the ones associated with the low-fractal stimuli.

By showing that processing fluency and complexity are not always negatively related, these findings are a first step in the reconciliation of the ideas and findings of fluency theory on the one hand and theories predicting a non-negative (positive or curvilinear) relation between aesthetic appreciation and complexity on the other hand. More specifically, the internal order present in a stimulus of high complexity (in the study of Joye and colleagues in the form of internal repetition) is expected to promote higher processing fluency and consequently also higher aesthetic appreciation. Within the framework of a balance between order and complexity, the high level of order (internal repetition) is considered to compensate for high level of complexity in the high-fractal stimuli, leading to higher aesthetic appreciation.

Predictive coding account of visual art. Van de Cruys and Wagemans (2011) proposed to look at aesthetic appreciation from a predictive coding perspective. From this perspective, individuals constantly make predictions about what to expect in the (visual) environment. These predictions are compared to the incoming sensory input. When predictions and input do not match, prediction errors occur. The predictive coding account of visual art proposes that aesthetic appreciation is related to successful reduction of these prediction errors. Similar to the perspective of balancing order and complexity, this account 
predicts interindividual differences in an optimal point (see next section): It predicts that each individual has its own optimal, preferred amount of unpredictability. Too much unpredictability will lead to unpleasantness or confusion, whereas too much predictability will lead to boredom (note the similarity to Arnheim, 1966). We believe that this approach is in accordance with the perspective of balancing order and complexity. If unpredictability is viewed as influenced by both order and complexity (i.e., order increasing predictability, complexity decreasing predictability), then the two views are equivalent in their predictions. Other authors have specified similar ideas concerning insights leading to aesthetic appreciation (e.g., Chetverikov \& Kristjánsson, 2016; Consoli, 2016; Kesner, 2014; Muth \& Carbon, 2013, 2016).

Pleasure-Interest Model of Aesthetic Liking. The Pleasure-Interest Model of Aesthetic Liking (PIA model; Graf \& Landwehr, 2015) distinguishes between pleasure-based and interest-based liking. It suggests a dual-process perspective on aesthetics, in which the first is stimulus-driven automatic processing and the second is perceiver-driven controlled processing. Immediate automatic processing is hypothesized to relate to pleasure, driven by a "gut-level fluency experience", similar to the processing fluency perspective presented above. Perceiver-driven controlled processing is hypothesized to relate to evaluations of interest, triggered by a disfluency reduction. In a recent addition to the theory, Graf and Landwehr (2017) suggested that both pleasure and interest mediate the relationship between stimulus fluency and aesthetic liking.

Considering the relation between the PIA model and the principle of the balance between order and complexity, we suggest that evaluations of interest (for rather complex, disfluent stimuli) only occur under perceiver-driven controlled processing because the 'order' resulting from the controlled processing (i.e., disfluency reduction) is necessary to counterbalance the complexity level of the stimulus. In contrast, evaluations of pleasure (for rather simple, fluent stimuli) do not ask for as much counterbalancing order, and thus proceed automatically and pleasure can be appreciated immediately. This division between spontaneous first impressions and later evaluative categorization is supported by electrophysiological evidence in research by Jacobsen and Höfel (2003; see als Höfel \& Jacobsen, 2007).

More comprehensive models of aesthetic appreciation. Also more comprehensive theories of aesthetic appreciation include order and complexity in their models. In the model of aesthetic appreciation and aesthetic judgments by Leder, Belke, Oeberst, and Augustin (2004), the principles of complexity and order are mentioned in the perceptual analysis of the 
stimulus (the first processing stage). Furthermore, the more conceptual and semantic types of order and complexity could play a role in later stages of the model (e.g., explicit classification, cognitive mastering), although this is not explicitly mentioned by Leder et al. (2004). More recently, a new model of art perception was proposed: The Vienna Integrated Model of Art Perception (VIMAP; Pelowski, Markey, Forster, Gerger, \& Leder, 2017). In VIMAP, order and complexity are first detected in the second processing stage (i.e., perceptual analysis) but further processed in the third stage of the model (i.e., implicit memory integration). In neither of these more comprehensive models a specific relation between order and complexity is proposed.

\section{Individual Differences in Aesthetic Appreciation, Order, and Complexity}

Individual differences do not only play an important role in determining aesthetic appreciation as such (e.g., Güçlütürk et al., 2016; Jacobsen, 2004; Vessel \& Rubin, 2010); they may also affect the perception of order and complexity, and in that way also affect aesthetic appreciation (see Figure 4). Furthermore, the type and strength of relationships between different aspects of order, complexity, and aesthetic appreciation may be subject to individual differences (e.g., Nadal, 2007).

\section{Individual differences in ...}

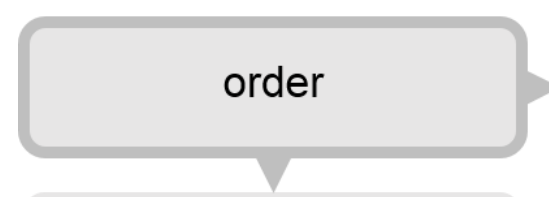

relation between order and aesthetic appreciation relation between order and complexity

aesthetic appreciation complexity

relation between complexity and aesthetic appreciation

Figure 4. Schematic representation of possible individual differences in aesthetic appreciation, order, and complexity. Figure licensed under CC BY 4.0 by the authors. Retrieved from https://doi.org/10.6084/m9.figshare.6144410.

Individual differences in aesthetic appreciation. Eysenck (1942) already specified four types of individual difference factors influencing aesthetic appreciation. He proposed two general factors and two 'unique' factors (i.e., peculiar to each observer). The first general factor, the ' $\mathrm{T}$ '-factor (originally referring to good ' $\mathrm{T}$ 'aste), was conceptualized as an innate factor of aesthetic appreciation (Eysenck, 1942). It has some resemblance to the general intelligence factor ' $\mathrm{g}$ ', in the sense that individuals vary in their 'ability' for aesthetic appreciation. The second general factor, the ' $\mathrm{K}$ '-factor, distinguished people preferring simple and ordered stimuli from people preferring more complex and less ordered stimuli (Nadal, 
2007). Eysenck (1942) related the ' $\mathrm{K}$ '-factor to the personality dimension of introversion (preferring simply, highly unified stimuli) versus extraversion (preferring complex, more diversified stimuli). Regarding the two 'unique' factors (i.e., peculiar to each observer), Eysenck (1942) distinguished 'specific' and 'error' factors. Specific factors include those based on private associations and experiences, while 'error' factors indicate those that show intraindividual variability.

In what follows, we will focus on interindividual differences related to (the balance between) order and complexity. Besides showing evidence that large individual differences in the perception and aesthetic appreciation of order and/or complexity exist, we will discuss some factors that may explain these individual differences (see also Table 3). Of course, we acknowledge that some of the factors mentioned under this section can also have an influence on aesthetic appreciation in general (e.g., Openness to Experience, art expertise).

\begin{tabular}{|c|c|}
\hline Individual difference factor & Example studies \\
\hline \multicolumn{2}{|c|}{ Individual difference factors related to the ... } \\
\hline perceptual and processing ability & $\begin{array}{l}\text { Chevrier \& Delorme (1980); Munsinger \& Kessen } \\
\text { (1964); Sherman, Grabowecky, \& Suzuki (2015) }\end{array}$ \\
\hline Big Five personality traits & $\begin{array}{l}\text { Chamorro-Premuzic, Burke, Hsu, \& Swami (2010); } \\
\text { Rentfrow \& Gosling (2003) }\end{array}$ \\
\hline need for cognitive structuring & $\begin{array}{l}\text { Bardi, Guerra, \& Ramdeny (2009); Berenbaum, } \\
\text { Bredemeier, \& Thompson (2008); Buhr \& Dugas } \\
\text { (2006); Neuberg \& Newsom (1993) }\end{array}$ \\
\hline level of education & Francès (1976) \\
\hline expertise & $\begin{array}{l}\text { Munsinger \& Kessen (1964); Nadal (2007); Orr \& } \\
\text { Ohlsson (2005) }\end{array}$ \\
\hline creativity & $\begin{array}{l}\text { Barron \& Welsh (1952); Eisenman \& Grove } \\
\text { (1972); Taylor \& Eisenman (1964) }\end{array}$ \\
\hline personality disorders & $\begin{array}{l}\text { King, Villeneuve, Post, Flowers, \& Moonshine } \\
\text { (1995) }\end{array}$ \\
\hline ... aesthetic appreciation of orde & \\
\hline expertise & Palmer \& Griscom (2013) \\
\hline obsessive-compulsive tendencies & Radomsky \& Rachman (2004) \\
\hline
\end{tabular}


age

gender

definitions of order and complexity
Chipman \& Mendelson (1979)

Nadal (2007)

Oliva et al. (2004)

Table 3. Relations between individual differences in personality and in order and complexity.

Individual differences in the aesthetic appreciation of complexity. Large individual differences in the aesthetic appreciation of complexity have been found in several studies (e.g., Aitken, 1974; Güçlütürk et al., 2016; Jacobsen \& Höfel, 2002; Tinio \& Leder, 2009). When no individual differences were taken into account and only average relations were examined, Aitken (1974) found an inverted U-shaped relationship between complexity of random polygons and judgments of pleasingness. However, when looking at the individual participants, very diverse patterns emerged. In the same vein, Güçlütürk et al. (2016) argued that the inverted U-shaped function between complexity and liking is the result of averaging very different individual functions between complexity and liking. Whereas one group of participants showed a negative relationship between complexity ratings for several digitally generated grayscale images and liking, another group of participants demonstrated a positive relationship. Although these studies support the existence of individual differences in the aesthetic appreciation of complexity, they do not specify individual difference factors that could explain these diverging patterns. Below we discuss some personality and other individual difference variables that have been found to be important in the aesthetic appreciation of complexity. We do not claim this to be an exhaustive list of all factors that are possibly involved.

Perceptual ability and processing ability. Chevrier and Delorme (1980) related individual differences in the aesthetic appreciation of complexity to individual differences in perceptual ability. They reported that children scoring high on an overlapping figures test and an embedded figures test preferred stimuli of a higher level of complexity than low scoring children. Sherman, Grabowecky, and Suzuki (2015) found evidence that aesthetic appreciation is higher for artworks of a level of visual complexity that is compatible with the individual's working memory capacity. More specifically, they showed that individuals with lower visual working memory capacity tended to prefer artworks of a lower level of visual complexity than individuals with higher visual working memory capacity. Munsinger and Kessen (1964) reported that participants preferred an amount of cognitive uncertainty that matched their processing ability. Taken together, both differences in perceptual ability and 
processing ability seem to be related to aesthetic preferences for different levels of complexity.

Big Five personality traits. Besides individual differences in abilities, also individual differences in personality may relate to aesthetic preferences. Openness to Experience is not only related to a preference for art in general (Chamorro-Premuzic, Burke, Hsu, \& Swami, 2010), it is also the Big Five trait that is most consistently found to relate to aesthetic preferences for complexity (e.g., in music: Rentfrow \& Gosling, 2003; in works of art: Chamorro-Premuzic et al., 2010). Chamorro-Premuzic et al. (2010) additionally found a negative association between Conscientiousness and a preference for subjectively complex paintings (i.e., paintings that were perceived as containing many sophisticated and interconnected elements). Although Chamorro-Premuzic et al. (2010) predicted a positive association between Extraversion and preference for complexity and a negative association between Neuroticism and preference for complexity, their results did not support these last two hypotheses.

Need for cognitive structuring. A personality trait that seemed possibly more closely related to an individual's preferred level of complexity than the very general Big Five personality traits, is an individual's desire for closure. The need for cognitive closure is defined by Kruglanski (1990) as a desire for an answer, no matter which answer, in contrast to staying in a confused or ambiguous state. Cognitive closure allows individuals to predict future situations and to act based on these predictions. Related concepts are intolerance of ambiguity and intolerance of uncertainty. Intolerance of ambiguity refers to the tendency of an individual to interpret a present situation that is ambiguous (e.g., novel, complex, insoluble, unpredictable, uncertain) as a threat or a source of discomfort (Grenier, Barrette, \& Ladouceur, 2005). Previous studies reported a negative correlation of ambiguity intolerance with Openness to Experience (Bardi, Guerra, \& Ramdeny, 2009) and with self-oriented perfectionism (Buhr \& Dugas, 2006). Intolerance of uncertainty resembles the concept of intolerance of ambiguity but is more oriented toward future situations (Dugas et al., 2005). Uncertainty intolerance correlated positively with ambiguity intolerance, several aspects of the need for cognitive closure, Neuroticism, and Conscientiousness (Berenbaum, Bredemeier, \& Thompson, 2008; Buhr \& Dugas, 2006). 
Cognitive structuring, described by Neuberg and Newsom (1993) as a way to reduce informational quantity and complexity, is one way to reach cognitive closure ${ }^{4}$. By creating and using abstract mental generalizations of previous experiences, individuals can understand the world without spending too much of their cognitive resources. The concept of a personal need for structure taps into the preference for structure and clarity as well as into reactions related to the absence of structure and clarity (Thompson, Naccarato, Parker, \& Moskowitz, 2001). Neuberg and Newsom (1993) found that individuals scoring high on a measure of the personal need for structure tend to organize both social and non-social information in less complex ways than low scoring individuals. Furthermore, a person's need for structure related to a preference for predictability (Webster \& Kruglanski, 1994) and to several Big Five factors. Neuberg and Newsom (1993) reported that a personal need for structure correlated negatively with Openness to Experience. Furthermore, the aspect related to a desire and preference for structure was positively associated with Conscientiousness, whereas the aspect related to negative reactions towards a lack of structure was positively associated with Neuroticism and negatively associated with Extraversion (Neuberg \& Newsom, 1993).

Education level. When examining aesthetic preferences of students and manual workers, Francès (1976) found that students preferred complex stimuli over simple ones, whereas preferences for manual workers were reversed. When Francès (1976) looked at specific aspects determining aesthetic preferences, there were no differences between the groups for the preferred number of elements or the preferred level of heterogeneity of elements. However, differences between groups were significant for four other aspects of complexity. Francès (1976) argued that these differences could be explained based on the long-term novelty principle: Manual workers may not have had enough experience with the more complex types of stimuli to be able to aesthetically appreciate them in a positive way.

Expertise. "The more energetic and masterful the mind, the more it will demand that the material of its art be really complex" (Moore, 1917, p. 135). Orr and Ohlsson (2005) found relationships between complexity and aesthetic appreciation of jazz and bluegrass improvisations for non-experts but not for expert musicians in the field. Munsinger and Kessen (1964) reported influences of experience on the relation between complexity and aesthetic appreciation, both when resulting from specific professional training and when induced experimentally. In general, most studies found positive associations between art

\footnotetext{
${ }^{4}$ Another way to reach cognitive closure that Neuberg and Newsom (1993) described is avoiding encountering new information.
} 
training and preferences for complexity (for a review, see Nadal, 2007). Furthermore, it has been suggested that art expertise may be positively associated with certain personality traits (e.g., Openness to Experience, need for cognition, and ambiguity tolerance; Belke, Leder, \& Carbon, 2015).

Creativity. Taylor and Eisenman (1964) compared how more and less creative art students responded to polygons of varying complexity. As was predicted, more creative participants preferred polygons of a greater level of complexity, and also judged more complex stimuli as the most meaningful, than less creative participants. Furthermore, more creative students produced more complex designs than their less creative peers. Interestingly, self-ratings of creativity correlated inversely with a preference for complexity (i.e., a high score on the question "How creative are you?" related positively with a dislike of complexity, $r=.34, p<.01$, and a liking of simplicity, $r=.25, p<.05$ ), whereas self-report about the number of instances of creative behaviors correlated slightly positive with liking complexity and disliking simplicity (Eisenman \& Grove, 1972). Barron and Welsh (1952) compared artists and non-artists and found evidence for artists liking complex-asymmetrical figures and disliking simple-symmetrical ones.

Personality disorders. Some personality disorders have been related to the appreciation of complexity. King, Villeneuve, Post, Flowers, and Moonshine (1995) found positive associations between the narcissistic and borderline personality disorders and the aesthetic appreciation of complexity, whereas dependent personality disorder was negatively related to the appreciation of complexity.

Individual differences in the aesthetic appreciation of order (harmony). Although no studies have examined individual differences in the aesthetic appreciation of order directly, as far as we know, Palmer and Griscom (2013) examined the preference for harmonious stimuli (i.e., in the sense of being "good Gestalts") on four different dimensions (i.e., color, shape, spatial location, and music). They found strong correlations across the different domains. In other words, individuals with a high preference for harmony on the color dimension also tended to prefer more harmony on the other dimensions than individuals with a lower preference for harmony. Specific training in a domain (i.e., spatial harmony for art training or musical harmony for music training) seemed to be related negatively to preference for harmony scores in that domain (Palmer \& Griscom, 2013). Additionally, Palmer and Griscom (2013) argued that whether and how individual differences in the preference for harmony and complexity might be related could be an important aspect for further research. Below we list 
some individual difference factors that could influence an individual's aesthetic appreciation of order.

Obsessive-compulsive tendencies. As obsessive-compulsive personality disorder (OCPD) is related to perfectionism and a preoccupation with details, order, and organization (American Psychiatric Association [APA], 2013 in Crego, Samuel, \& Widiger, 2015) and compulsive ordering and arranging is one of the symptoms of obsessive-compulsive disorder (OCD; Radomsky \& Rachman, 2004), it is hypothesized that obsessive-compulsive tendencies could be related to an aesthetic preference for order. Also Radomsky and Rachman (2004) argued that compulsive ordering and a drive for symmetry in OCD could be seen as extreme instances of a common preference for order and symmetry ${ }^{5}$. Obsessions and compulsions are known to occur in non-clinical populations (Gibbs, 1996). Radomsky and Rachman (2004) showed that the strength of the preference for pictures of orderly environments above pictures of disorderly environments correlated strongly positive with a measure of symmetry, ordering, and arranging behavior.

In a review of research on OCD in non-clinical populations, Gibbs (1996) reported positive correlations between obsessive-compulsive symptoms and personality traits as neuroticism, introversion, and the need for control. Crego et al. (2015) found support for the statement that OCPD might be seen as a maladaptive variant of conscientiousness.

Individual differences in the perception of order and complexity. Individuals cannot only differ in how much they aesthetically appreciate a certain level of order, complexity, or the balance between order and complexity, they can also differ in their perception of order and complexity as such. This could be influenced by several factors, including age, gender, or the definitions of order and complexity used by the individual.

Age. Chipman and Mendelson (1979) reported that sensitivity for different types of organization developed at different ages. They concluded that the type of organization present in a stimulus is important in understanding age-related differences in the perception of complexity. In other words, because young children do not pay attention yet to all types of organization, their perceived complexity scores may in some cases be determined more heavily by quantitative variables (rather than structural variables) than the scores of adults.

Gender. Nadal (2007) found that men and women differed in which aspects of complexity had the most influence on their perceived complexity ratings, at least for some

\footnotetext{
${ }^{5}$ Furthermore, they did not expect any differences in ordering and arranging behavior in OCD and OCPD, although it might have different functions in both disorders (Radomsky \& Rachman, 2004).
} 
types of stimuli (not for abstract decorative stimuli). Complexity scores given by men were best predicted by the number of elements in the stimuli and the variety of elements in the stimuli. The complexity scores given by women were best predicted by women's ratings of the number of elements in the stimuli and the variety of colours in the stimuli.

Definitions of order and complexity. Oliva et al. (2004) asked participants to hierarchically group images of real-world indoor scenes based on visual complexity. At each grouping stage participants had to describe the criteria they used for the categorization. When visual complexity was defined as related to how difficult it would be to remember the image and to give a verbal description of the image, participants reported criteria related to the number and variety of elements in the images. When visual complexity was defined as related to the structure of the scene image, participants gave more weight to dimensions related to order (i.e., clutter, symmetry, open space, and organization). Consequently, it could be that different individuals use different standard definitions of order and complexity, influencing their subjective ratings of the concepts (and possibly aesthetic appreciation).

\section{Conclusions}

Throughout history, order (i.e., aspects related to the structure and organization of information in a stimulus), complexity (i.e., aspects related to the quantity and variety of information in a stimulus), and the balance between order and complexity have often been proposed as determinants or indicators of aesthetic appreciation. Although it became clear that there is a relationship of those constructs with appreciation, the nature and type of this relationship are less clear. This could be due to several factors, including differences in how order, complexity, their interplay, and aesthetic appreciation are defined and operationalized, not taking into account the multidimensionality of the concepts involved, not controlling for differences in order in studies on complexity (or the other way around), and/or the specific stimuli and participants used in each study. In addition, individuals can differ in various ways, including how they perceive order and complexity, but also how their perceptions of order and complexity relate to their feelings of aesthetic appreciation. To go beyond the diversity in results depending on many theoretical and methodological choices, as well as randomly emerging differences between studies, we propose an integrative view on the theoretical and empirical literature concerning this topic.

We propose that both order and complexity are important in determining, or at least predicting, aesthetic appreciation. As order and complexity can be viewed as both complementary and antagonistic, it is important to study their relation to aesthetic appreciation together, not separately. The combination of or balance between order and 
complexity (i.e., either additive or interactive) is expected to influence aesthetic appreciation following an optimal point perspective: When the balance between order and complexity is optimal, aesthetic appreciation will be highest. Appreciation will be lower when the amount of order relative to the amount of complexity is either too low or too high. Alternatively, there could be two separate optimal points: one for order and one for complexity. This could be the case when order and complexity would be additive rather than interactive. In addition, we believe that this optimal point of balance can be subject to individual differences, which can at least partly be explained by (or correlated with) other individual differences like, for example, perceptual abilities, processing abilities, or expertise.

The view we propose, or at least the predictions resulting from this view, can be related to several other theoretical views on aesthetic appreciation, and reconciled with them. Furthermore, many questions are still open for further investigation and reflection. Some of these considerations will be pointed out below.

\section{Testing the Relations Between Order, Complexity, and Appreciation}

Order and complexity as partial opposites. One can empirically test whether order reduces complexity by systematically varying levels of order in a stimulus while keeping the level of complexity constant (at low, intermediate, and high levels of complexity) and investigating whether perceived complexity scores decrease when order is high. Equivalently, it can be tested whether complexity reduces order by varying complexity levels while keeping the order level constant (at low, intermediate, and high levels) and investigating whether perceived order scores decrease when complexity is high. Furthermore, it is important to take into account the multidimensionality of order and complexity here: both the structure and organization in the stimulus as well as the quantity and variety of information in the stimulus can be varied in multiple ways, and different aspects of order and complexity can relate in different ways.

Order and complexity as partial complements. That order needs complexity to show its potential can be tested by investigating whether more complex stimuli show a broader range of quantitatively different (dis)order levels than less complex stimuli. That complexity needs order to be understood and appreciated can be tested by asking participants to indicate their appreciation for stimuli of varying levels of order while keeping the complexity level constant.

The balance between order and complexity as important factor for appreciation.

That both order and complexity are important for aesthetic appreciation can be tested by investigating whether a model including both factors can predict participants' aesthetics 
scores better than a model including only order or complexity. The same strategy can be taken for determining whether the interaction between order and complexity is important in predicting appreciation: compare whether a model including the interaction predicts aesthetic ratings better than a model without the interaction. As indicated before, however, it is important that the possible added value of the interaction term can depend on which stimuli and which operationalizations of order and complexity are used.

\section{Future Considerations in Relating Order, Complexity, and Aesthetic Appreciation}

Factors influencing subjective order and complexity. If we assume that aesthetic appreciation is at least partially dependent on subjective order and complexity, the next question to ask is which factors subjective order and complexity are dependent on (e.g., objective order and complexity factors), and how this differs between individuals. In future studies, it is therefore worthwhile to further investigate the founding factors underlying subjective reports of order and complexity.

\section{Subjective order and complexity as cause or correlate of aesthetic appreciation?} In addition, one could consider whether subjective order and complexity are the basic building stones influencing aesthetic appreciation, or whether subjective order, subjective complexity, and aesthetic appreciation are all direct consequences of a common underlying process based on the current conditions (e.g., stimulus conditions like objective order and complexity factors). The latter would imply that those measures only differ in how they combine or balance those different objective factors; the former would imply that aesthetic appreciation is on a 'higher' processing level than perceptions of order and complexity. In future studies, it is therefore worthwhile to try to discriminate between those possibilities. Nevertheless, regardless of whether subjective order and complexity are the cause or only a correlate of aesthetic appreciation, they can be very useful in predicting aesthetic appreciation.

Combination of or balance between (subjective) order and complexity? Based on the literature, the relation between order and complexity seems to be both complementary and antagonistic. This could make correlations between order and complexity very dependent on the specific type and specific set of stimuli used. What is unclear at the moment, is whether order and complexity have independent relations with aesthetic appreciation or instead interact in their relation to aesthetic appreciation. In other words, it is unclear whether it is necessary to specify a balance between order and complexity, or whether good predictions can be made based on the separate effects of order and complexity. In future studies, it is 
therefore worthwhile to further investigate whether the relations of order and complexity with aesthetic appreciation are (in)dependent from each other.

Different types of aesthetic appreciation. Just like order and complexity, aesthetic appreciation is not a one-dimensional construct. As in the PIA model (Graf \& Landwehr, 2015, 2017), some types of aesthetic appreciation could be related more closely to pleasure, whereas others could be more closely related to interest. In future studies, it is therefore worthwhile to distinguish clearly between different types of aesthetic appreciation and their distinct relations to order and complexity.

Different theories of aesthetic appreciation. As indicated, very diverse theories of aesthetic appreciation include (the balance between) order and complexity in some way. From several of these theories, similar predictions can be made. One additional challenge for the future will be to propose studies that are able to distinguish between the different theoretical proposals, by refining how they differ and how differential predictions can be derived.

Aesthetics involves both stimulus and person. Research in experimental psychoaesthetics can focus on either stimulus or person properties determining aesthetic preferences (Wagemans, 2011), but an adequate theory of aesthetic preferences must include both, from an interactionist perspective (Mather, 2014). Although most studies of aesthetic preference aim to find stimulus properties influencing preferences of all individuals in the same way (Vessel \& Rubin, 2010), the influence of individual differences in aesthetic preference must not be neglected. Previous research has shown that individual differences in aesthetic preferences can be strong and that ignoring these by averaging over participants can lead to an inadequate representation or an incomplete interpretation of the acquired data (Güçlütürk, Jacobs, \& van Lier, 2016; Jacobsen, 2004; Vessel \& Rubin, 2010). We hope that based on this review and previous work (e.g., Vessel \& Rubin, 2010), it becomes clear that individual differences are important to take into account to come to better explanations of and predictions for aesthetic appreciation. In future studies, it is therefore worthwhile to investigate how both stimulus and person properties, and especially their interaction, influence or relate to aesthetic appreciation.

Clear specification of conditions and carefully testing generalizations. In general, we believe that a lot more specification of the prevailing context or conditions is necessary to learn in a consistent way about human aesthetics. Aesthetic appreciation relates to the whole context present rather than to the sum of separate parts of the experience or context (i.e., the 'Gestalt nightmare'; Arnheim, 1954/2004; Makin, 2017). Consequently, experiments manipulating one specific stimulus dimension do this within a specific context, and results of 
the study can be very specifically tied to that context. This, however, should not prevent researchers of making generalizations based on the theoretical and empirical literature, and carefully testing these generalizations in new studies. In future studies, it is therefore worthwhile to specify clearly the conditions under which the study took place, and to generalize findings on both theoretical and empirical grounds instead of only taking into account the results of the current study.

Aesthetics and arousal. In Berlyne's (1971) account, optimal arousal level is the key factor in determining aesthetic appreciation. It is not clear however whether arousal level indeed plays a crucial role in the formation of aesthetic experiences, and if so, how it would do so. Traditionally, it was suggested that complexity increases arousal whereas order reduces it. Research by Bertamini, Makin and Rampone (2013) at least questions this assumed relationship. They found an implicit association between symmetrical (i.e., ordered) patterns and words high in arousal, and between random (i.e., less ordered) patterns and words low in arousal. Before making strong predictions on how order and complexity would relate to arousal level, it seems necessary to clarify (a) what a low or high arousal level 'means' or signals for an organism; (b) how arousal level relates to aesthetic appreciation; and (c) why it would relate to appreciation in a certain way.

Dynamics over time. Although most work on aesthetics looks at stable relations between order, complexity, and aesthetic appreciation, each of them as well as their interaction can vary over time. As Muth and Carbon (2016, p. 173) indicated, it is necessary "to include temporal [...] dynamics of perception and appreciation in our conception". These temporal dynamics can in their turn add to our understanding of aesthetic appreciation and its relation to order and complexity.

Balancing ecological validity and experimental control. Research in experimental psycho-aesthetics often struggles with the challenge of balancing the needs for ecological validity and experimental control. In studies investigating the influence of order and complexity on aesthetic appreciation, maximizing experimental control by using simple stimuli has long been the dominant approach (Wagemans, 2011). This approach gives researchers the possibility to precisely control which factor is manipulated and it thereby enables them to determine which factor is responsible for the difference in aesthetic appreciation. However, the stimuli used are often that simple that they are not very relevant to aesthetic objects and images encountered in daily life, and could therefore neglect important determinants of real aesthetic behavior (Nadal, 2007). In contrast, other studies try to maximize ecological validity by using existing aesthetic stimuli, like art works or design 
objects (Wagemans, 2011). Although this increases ecological validity, it also diminishes experimental control and thereby the possibility to precisely determine the crucial differences between the different stimuli presented (Nadal, 2007). In future studies, it is therefore worthwhile to consider several convergent methodological approaches, varying in their position on the dimension ecological validity - experimental control.

\section{Take Home Message}

This review suggests that both order, related to the structure and organization of information (an individual perceives) in a stimulus, and complexity, related to the quantity and variety of information (an individual perceives) in a stimulus, are important in predicting aesthetic appreciation. Although order and complexity need each other to be appreciatedorder without complexity is too boring and complexity without order too confusing - they also reduce each other's strength. Therefore, it is important to study their relation to aesthetic appreciation together, not separately. 


\section{References}

Abeln, J., Fresz, L., Amirshahi, S. A., McManus, I. C., Koch, M., Kreysa, H., \& Redies, C. (2016). Preference for well-balanced saliency in details cropped from photographs. Frontiers in Human Neuroscience, 9, 704. doi:10.3389/fnhum.2015.00704

Adkins, O. C., \& Norman, J. F. (2016). The visual aesthetics of snowflakes. Perception, 45, 1304-1319. doi:10.1177/2041669516661122

Aitken, P. P. (1974). Judgments of pleasingness and interestingness as functions of visual complexity. Journal of Experimental Psychology, 103, 240-244. doi:10.1037/h0036787

Amirshahi, S. A., Hayn-Leichsenring, G. U., Denzler, J., \& Redies, C. (2014). Evaluating the rule of thirds in photographs and paintings. Art \& Perception, 2, 163-182. doi:10.1163/22134913-00002024

Arnheim, R. (2004). Art and visual perception: A psychology of the creative eye, fiftieth anniversary printing (Rev. ed.). Berkeley and Los Angeles, CA: University of California Press. (Original work published 1954)

Arnheim, R. (1966). Order and complexity in landscape design. In R. Arnheim (Ed.), Toward a psychology of art: Collected essays (pp. 123-135). Berkeley and Los Angeles, CA: University of California Press.

Arnheim, R. (1971). Entropy and art: An essay on disorder and order. Berkeley and Los Angeles, CA: University of California Press.

Attneave, F. (1957). Physical determinants of the judged complexity of shapes. Journal of Experimental Psychology, 53, 221-227. doi:10.1037/h0043921

Bardi, A., Guerra, V. M., \& Ramdeny, G. S. D. (2009). Openness and ambiguity intolerance: Their differential relations to well-being in the context of an academic life transition. Personality and Individual Differences, 47, 219-223. doi:10.1016/j.paid.2009.03.003

Barron, F., \& Welsh, G. S. (1952). Artistic perception as a possible factor in personality style: Its measurement by a figure preference test. The Journal of Psychology, 33, 199-203. doi:10.1080/00223980.1952.9712830

Belke, B., Leder, H., \& Carbon, C. C. (2015). When challenging art gets liked: Evidences for a dual preference formation process for fluent and non-fluent portraits. PLoS ONE, 10, e0131796. doi:10.1371/journal.pone.0131796

Berlyne, D. E. (1960). Conflict, arousal and curiosity. New York, NY: McGraw-Hill.

Berlyne, D. E. (1971). Aesthetics and Psychobiology. New York, NY: Appleton-CenturyCrofts. 
Berlyne, D. E., Ogilvie, J. C., \& Parham, L. C. C. (1968). The dimensionality of visual complexity, interestingness, and pleasingness. Canadian Journal of Psychology, 22, 376-387. doi:10.1037/h0082777

Birkhoff, G. D. (1933). Aesthetic measure. Cambridge, MA: Harvard University Press.

Boselie, F., \& Leeuwenberg, E. (1985). Birkhoff revisited: Beauty as a function of effect and means. American Journal of Psychology, 98, 1-39. doi:10.2307/1422765

Berenbaum, H., Bredemeier, K., \& Thompson, R. J. (2008). Intolerance of uncertainty: Exploring its dimensionality and associations with need for cognitive closure, psychopathology, and personality. Journal of Anxiety Disorders, 22, 117-125. doi:10.1016/j.janxdis.2007.01.004

Bertamini, M., Silvanto, J., Norcia, A. M., Makin, A. D. J., \& Wagemans, J. (2018). The neural basis of visual symmetry and its role in mid- and high-level visual processing. Annals of the New York Academy of Sciences, 1426, 111-126. doi:10.1111/nyas.13667

Braun, J., Amirshahi, S. A., Denzler, J., \& Redies, C. (2013). Statistical image properties of print advertisements, visual artworks and images of architecture. Frontiers in Psychology, 4, 808. doi:10.3389/fpsyg.2013.00808

Buhr, K., \& Dugas, M. J. (2006). Investigating the construct validity of intolerance of uncertainty and its unique relationship with worry. Journal of Anxiety Disorders, 20, 222-236. doi:10.1016/j.janxdis.2004.12.004

Cardaci, M., Di Gesù, V., Petrou, M., \& Tabacchi, M. E. (2009). Attentional vs. computational complexity measures in observing paintings. Spatial Vision, 22, 195209. doi:10.1163/156856809788313138

Cárdenas, R. A., \& Harris, L. J. (2006). Symmetrical decorations enhance the attractiveness of faces and abstract designs. Evolution and Human Behavior, 27, 1-18. doi:10.1016/j.evolhumbehav.2005.05.002

Cavalcante, A., Mansouri, A., Mansouri, L. K. E., Barros, A. K., Takeuchi, Y., Matsumoto, N., \& Ohnishi, N. (2011). On the relation between contrast and the perception of visual complexity. Proceedings of the 21st Annual Conference of the Japanese Neural Network Society. Retrieved from http://jnns.org/conference/misc/camera_ready/P222.pdf.

Chamorro-Premuzic, T., Burke, C., Hsu, A., \& Swami, V. (2010). Personality predictors of artistic preferences as a function of the emotional valence and perceived complexity of paintings. Psychology of Aesthetics, Creativity, and the Arts, 4, 196-204. doi:10.1037/a0019211 
Chetverikov, A., \& Kristjánsson, Á. (2016). On the joys of perceiving: Affect as feedback for perceptual predictions. Acta Psychologica, 169, 1-10. doi:10.1016/j.actpsy.2016.05.005

Chevrier, J., \& Delorme, A. (1980). Aesthetic preferences: Influence of perceptual ability, age and complexity of stimulus. Perceptual and Motor Skills, 50, 839-849. doi:10.2466/pms.1980.50.3.839

Chikhman, V., Bondarko, V., Danilova, M., Goluzina, A., \& Shelepin, Y. (2012). Complexity of images: Experimental and computational estimates compared. Perception, 41, 631647. doi:10.1068/p6987

Chipman, S. F. (1977). Complexity and structure in visual patterns. Journal of Experimental Psychology: General, 106, 269-301. doi:10.1037/0096-3445.106.3.269

Chipman, S. F., \& Mendelson, M. J. (1979). Influence of six types of visual structure on complexity judgments in children and adults. Journal of Experimental Psychology: Human Perception and Performance, 5, 365-378. doi:10.1037/0096-1523.5.2.365

Chmiel, A., \& Schubert, E. (2017). Back to the inverted-U for music preference: A review of the literature. Psychology of Music, 45, 886-909. doi:10.1177/0305735617697507

Consoli, G. (2016). Predictive error reduction and the twofold nature of aesthetic pleasure. Art \& Perception, 4, 327-338. doi:10.1163/22134913-00002058

Corchs, S. E., Ciocca, G., Bricolo, E., \& Gasparini, F. (2016). Predicting complexity perception of real world images. PLoS ONE, 11, e0157986. doi:10.1371/journal.pone.0157986

Crego, C., Samuel, D. B., \& Widiger, T. A. (2015). The FFOCI and other measures and models of OCPD. Assessment, 22, 135-151. doi:10.1177/1073191114539382

Cupchik, G. C. (1986). A decade after Berlyne: New directions in experimental aesthetics. Poetics, 15, 345-369. doi:10.1016/0304-422X(86)90003-3

Deng, L., \& Poole, M. S. (2012). Aesthetic design of e-commerce web pages - Webpage Complexity, Order and preference. Electronic Commerce Research and Applications, 11, 420-440. doi:10.1016/j.elerap.2012.06.004

Dugas, M. J., Hedayati, M., Karavidas, A., Buhr, K., Francis, K., \& Phillips, N. A. (2005). Intolerance of uncertainty and information processing: Evidence of biased recall and interpretations. Cognitive Therapy and Research, 29, 57-70. doi:10.1007/s10608-005$1648-9$

Donderi, D. C. (2006a). Visual complexity: A review. Psychological Bulletin, 132, 73-97. doi:10.1037/0033-2909.132.1.73 
Donderi, D. C. (2006b). An information theory analysis of visual complexity and dissimilarity. Perception, 35, 823-835. doi:10.1068/p5249

Eisenman, R., \& Gellens, H. (1968). Preferences for complexity-simplicity and symmetryasymmetry. Perceptual and Motor Skills, 26, 888-890. doi:10.2466/pms.1968.26.3.888

Eisenman, R., \& Grove, M. S. (1972). Self-ratings of creativity, semantic differential ratings, and preferences for polygons varying in complexity, simplicity, and symmetry. The Journal of Psychology, 81, 63-67. doi:10.1080/00223980.1972.9923789

Eisenman, R., \& Rappaport, J. (1967). Complexity preference and semantic differential ratings of complexity-simplicity and symmetry-asymmetry. Psychonomic Science, 7, 147-148. doi:10.3758/BF03328508

Eysenck, H. J. (1941). 'Type'-factors in aesthetic judgements. British Journal of Psychology, 31, 262-270. doi:10.1111/j.2044-8295.1941.tb00992.x

Eysenck, H. J. (1942). The experimental study of the 'good Gestalt'-A new approach. Psychological Review, 49, 344-364. doi:10.1037/h0057013

Fechner, G. T. (1876). Vorschule der Aesthetik [Elementary aesthetics]. Leipzig, Germany: Breitkopf \& Härtel.

Fisher, Y. (Ed.). (1995). Fractal image compression: Theory and application. London: Springer. doi:10.1007/978-1-4612-2472-3

Fletcher, N. H. (2012). The sound of music: Order from complexity. Acoustics Australia, 40, $188-193$.

Forsythe, A., Mulhern, G., Sawey, M. (2008). Confounds in pictorial sets: The role of complexity and familiarity in basic level pictures processing. Behavioral Research Methods, 40, 116-129. doi:10.3758/BRM.40.1.116

Forsythe, A., Nadal, M., Sheehy, N., Cela-Conde, C. J., \& Sawey, M. (2011). Predicting beauty: Fractal dimension and visual complexity in art. British Journal of Psychology, 102, 49-70. doi:10.1348/000712610X498958

Friedenberg, J., \& Liby, B. (2016). Perceived beauty of random texture patterns: A preference for complexity. Acta Psychologica, 168, 41-49. doi:10.1016/j.actpsy.2016.04.007

Gartus, A., \& Leder, H. (2017). Predicting perceived visual complexity of abstract patterns using computational measures: The influence of mirror symmetry on complexity perception. PLoS One, 12, e0185276. doi:10.1371/journal.pone.0185276 
Gibbs, N. A. (1996). Nonclinical populations in research on obsessive-compulsive disorder: A critical review. Clinical Psychology Review, 16, 729-773. doi:10.1016/S02727358(96)00043-8

Gilbert, K. E., \& Kuhn, H. (1972). A history of esthetics: Revised and enlarged (Rev. ed.). Westport, CT: Greenwood Press. (Original work published 1953)

Gombrich, E. H. (1992). The sense of order: A study in the psychology of decorative art (2nd ed.). London, England: Phaidon. (Original work published 1984)

Gordon, J., \& Gridley, M. C. (2013). Musical preferences as a function of stimulus complexity of piano jazz. Creativity Research Journal, 25, 143-146. doi:10.1080/10400419.2013.752303

Graf, L. K. M., \& Landwehr, J. R. (2015). A dual-process perspective on fluency-based aesthetics: The pleasure-interest model of aesthetic liking. Personality and Social Psychology Review, 19, 395-410. doi:10.1177/1088868315574978

Graf, L. K. M., \& Landwehr, J. R. (2017). Aesthetic pleasure versus aesthetic interest: The two routes to aesthetic liking. Frontiers in Psychology, 8, 15. doi:10.3389/fpsyg.2017.00015

Gray, K., Schmitt, P., Strohminger, N., \& Kassam, K. S. (2014). The science of style: In fashion, colors should match only moderately. PLOS ONE, 9, e102772. doi:10.1371/journal.pone.0102772

Grenier, S., Barrette, A.-M., \& Ladouceur, R. (2005). Intolerance of Uncertainty and Intolerance of Ambiguity: Similarities and differences. Personality and Individual Differences, 39, 593-600. doi:10.1016/j.paid.2005.02.014

Güçlütürk, Y., Jacobs, R. H. A. H., \& van Lier, R. (2016). Liking versus complexity: Decomposing the inverted U-curve. Frontiers in Human Neuroscience, 10, 112. doi:10.3389/fnhum.2016.00112

Hagerhall, C. M., Purcell, T., \& Taylor, R. (2004). Fractal dimension of landscape silhouette outlines as a predictor of landscape preference. Journal of Environmental Psychology, 24, 247-255. doi:10.1016/j.jenvp.2003.12.004

Höfel, L., \& Jacobsen, T. (2007). Electrophysiological indices of processing aesthetics: Spontaneous or intentional processes? International Journal of Psychophysiology, 65, 20-31. doi:10.1016/j.ijpsycho.2007.02.007

Hübner, R., \& Fillinger, M. G. (2016). Comparison of objective measures for predicting perceptual balance and visual aesthetic preference. Frontiers in Psychology, 7, 335. doi:10.3389/fpsyg.2016.00335 
Imamoglu, Ç. (2000). Complexity, liking and familiarity: Architecture and non-architecture Turkish students' assessments of traditional and modern house facades. Journal of Environmental Psychology, 20, 5-16. doi:10.1006/jevp.1999.0155

Jacobsen, T. (2004). Individual and group modelling of aesthetic judgment strategies. British Journal of Psychology, 95, 41-56. doi:10.1348/000712604322779451

Jacobsen, T., \& Höfel, L. (2002). Aesthetic judgments of novel graphic patterns: Analyses of individual judgments. Perceptual and Motor Skills, 95, 755-766. doi:10.2466/pms.2002.95.3.755

Jacobsen, T., \& Höfel, L. (2003). Descriptive and evaluative judgment processes: Behavioral and electrophysiological indices of processing symmetry and aesthetics. Cognitive, Affective, \& Behavioral Neuroscience, 3, 289-299. doi:10.3758/CABN.3.4.289

Jacobsen, T., Schubotz, R. I., Höfel, L., \& von Cramon, D. Y. (2006). Brain correlates of aesthetic judgment of beauty. NeuroImage, 29, 276-285. doi:10.1016/j.neuroimage.2005.07.010

Joye, Y., Steg, L., Ünal, A. B., \& Pals, R. (2016). When complex is easy on the mind: Internal repetition of visual information in complex objects is a source of perceptual fluency. Journal of Experimental Psychology: Human Perception and Performance, 42, 103 114. doi:10.1037/xhp0000105

Kesner, L. (2014). The predictive mind and the experience of visual art work. Frontiers in Psychology, 5, 1417. doi:10.3389/fpsyg.2014.01417

Koffka, K. (1940). Problems in the psychology of art. In R. Bernheimer, R. Carpenter, K. Koffka, \& M. C. Nahm (Eds.), Art: A Bryn Mawr Symposium. Bryn Mawr Notes and Monographs (Vol. IX, pp. 180-273). New York: Sentry Press.

Kovesi, P. (2003). Phase congruency detects corners and edges. In C. Sun, H. Taöbot, S. Ourselin, \& T. Adriaansen (Eds.), Proceedings of the VIIth Biennial Australian Pattern Recognition Society Conference: DICTA 2003 (pp. 309-318). Collingwood: CSIRO.

Kreitler, S., Zigler, E., \& Kreitler, H. (1974). The complexity of complexity. Human Development, 17, 54-73. doi:10.1159/000271333

Kruglanski, A. W. (1990). Motivations for judging and knowing: Implications for causal attribution. In E. T. Higgins \& R. M. Sorrentino (Eds.), The handbook of motivation and cognition: Foundation of social behaviour (Vol. 2, pp. 333-368). New York, NY: Guilford Press. 
Leder, H., Belke, B., Oeberst, A., \& Augustin, D. (2004). A model of aesthetic appreciation and aesthetic judgments. British Journal of Psychology, 95, 489-508. doi:10.1348/0007126042369811

Locher, P., Cornelis, E., Wagemans, J., \& Stappers, P. J. (2001). Artists' use of compositional balance for creating visual displays. Empirical Studies of the Arts, 19, 213-227. doi:10.2190/EKMD-YMN5-NJUG-34BK

Locher, P. J., Stappers, P. J., \& Overbeeke, K. (1998). The role of balance as an organizing design principle underlying adults' compositional strategies for creating visual displays. Acta Psychologica, 99, 141-161. doi:10.1016/S0001-6918(98)00008-0

Lyssenko, N., Redies, C., \& Hayn-Leichsenring, G. U. (2016). Evaluating abstract art: Relation between term usage, subjective ratings, image properties, and personality traits. Frontiers in Psychology, 7, 973. doi:10.3389/fpsyg.2016.00973

Machado, P., \& Cardoso, A. (1998). Computing aesthetics. In F. Oliveira (Ed.), XIVth Brazilian Symposium on Artificial Intelligence SBIA'98. LNAI Series (pp. 219-229). Porto Alegre, Brazil: Springer.

Machado, P., Romero, J., Nadal, M., Santos, A., Correia, J., \& Carballal, A. (2015). Computerized measures of visual complexity. Acta Psychologica, 160, 43-57. doi:10.1016/j.actpsy.2015.06.005

Makin, A. D. J. (2017). The gap between aesthetic science and aesthetic experience. Journal of Consciousness Studies, 24, 184-213.Manaris, B., Vaughan, D., Wagner, C., Romero, J., \& Davis, R. B. (2003). Evolutionary music and the Zipf-Mandelbrot Law: Developing fitness functions for pleasant music. In S. Cagnoni et al. (Eds.), Applications of Evolutionary Computing. Lecture Notes in Computer Science, 2611 (pp. 522-534). Berlin, Heidelberg: Springer.

Marin, M. M., \& Leder, H. (2013). Examining complexity across domains: Relating subjective and objective measures of affective environmental scenes, paintings and music. PLoS ONE, 8, e72412. doi:10.1371/journal.pone.0072412

Martindale, C., Moore, K., \& Borkum, J. (1990). Aesthetic preference: Anomalous findings for Berlyne's psychobiological theory. American Journal of Psychology, 103, 53-80. doi:10.2307/1423259

Mather, G. (2014). The psychology of visual art: Eye, brain and art. Cambridge, England: Cambridge University Press.

Mather, G. (2018). Visual image statistics in the history of Western art. Art \& Perception, 8. doi:10.1163/22134913-20181092 
Moore, H. T. (1917). Pain and pleasure. New York, NY: Moffat, Yard and Company.

Munsinger, H., \& Kessen, W. (1964). Uncertainty, structure, and preference. Psychological Monographs: General and Applied, 78(9), 1-24. doi:10.1037/h0093865

Mureika, J. R., \& Taylor, R. P. (2013). The abstract expressionists and les automatistes: a shared multi-fractal depth? Signal Processing, 93, 573-578. doi:10.1016/j.sigpro.2012.05.002

Muth, C., \& Carbon, C.-C. (2013). The aesthetic Aha: On the pleasure of having insights into Gestalt. Acta Psychologica, 144, 25-30. doi:10.1016/j.actpsy.2013.05.001

Muth, C., \& Carbon, C.-C. (2016). SeIns: Semantic instability in art. Art \& Perception, 4, 145-184. doi:10.1163/22134913-00002049

Muth, C., Raab, M. H., \& Carbon, C.-C. (2015). The stream of experience when watching artistic movies. Dynamic aesthetic effects revealed by the Continuous Evaluation Procedure (CEP). Frontiers in Psychology, 6, 365. doi:10.3389/fpsyg.2015.00365

Nadal, M. (2007). Complexity and aesthetic preference for diverse visual stimuli. (Doctoral thesis, Universitat de les Illes Balears, Spain). Retrieved from http://ibdigital.uib.cat/greenstone/cgi-bin/library.cgi

Nadal, M., Munar, E., Marty, G., \& Cela-Conde C. J. (2010). Visual complexity and beauty appreciation: Explaining the divergence of results. Empirical Studies of the Arts, 28, 173-191. doi:10.2190/EM.28.2.d

Nasar, J. L. (1994). Urban design aesthetics: The evaluative qualities of building exteriors. Environment and Behavior, 26, 377-401. doi:10.1177/001391659402600305

Neuberg, S. L., \& Newsom, J. T. (1993). Personal Need for Structure: Individual differences in the desire for simple structure. Journal of Personality and Social Psychology, 65, $113-131$.

Nicki, R. M., \& Moss, V. (1975). Preference for non-representational art as a function of various measures of complexity. Canadian Journal of Psychology, 29, 237-249. doi:10.1037/h0082029

North, A. C., \& Hargreaves, D. J. (1995). Subjective complexity, familiarity, and liking for popular music. Psychomusicology, 14, 77-93. doi:10.1037/h0094090

Oliva, A., Mack, M. L., Shrestha, M., \& Peeper, A. (2004). Identifying the perceptual dimensions of visual complexity of scenes. In K. Forbus, D. Gentner, \& T. Regier (Eds.), Proceedings of the Annual Meeting of the Cognitive Science Society, 26, 10411046. Retrieved from http://escholarship.org/uc/item/17s4h6w8 
Orr, M. G., \& Ohlsson, S. (2005). Relationship between complexity and liking as a function of expertise. Music Perception: An Interdisciplinary Journal, 22, 583-611. doi:10.1525/mp.2005.22.4.583

Palmer, S. E., \& Griscom, W. S. (2013). Accounting for taste: Individual differences in preference for harmony. Psychonomic Bulletin \& Review, 20, 453-461. doi:10.3758/s13423-012-0355-2

Palmer, S. E., Schloss, K. B., \& Sammartino, J. (2013). Visual aesthetics and human preference. Annual Review of Psychology, 64, 77-107. doi:10.1146/annurev-psych120710-100504

Palumbo, L., Ogden, R., Makin, A. D. J., \& Bertamini, M. (2014). Examining visual complexity and its influence on perceived duration. Journal of Vision, 14(14), 3. doi:10.1167/14.14.3

Phillips, F., Norman, J. F., \& Beers, A. M. (2010). Fechner's aesthetics revisited. Seeing and Perceiving, 23, 263-271. doi:10.1163/187847510X516412

Post, R. A. G., Blijlevens, J., \& Hekkert, P. (2016). 'To preserve unity while almost allowing for chaos': Testing the aesthetic principle of unity-in-variety in product design. Acta Psychologica, 163, 142-152. doi:10.1016/j.actpsy.2015.11.013

Post, R., Nguyen, T., \& Hekkert, P. (2017). Unity in variety in website aesthetics: A systematic inquiry. International Journal of Human-Computer Studies, 103, 48-62. doi:10.1016/j.ijhcs.2017.02.003

Radomsky, A. S., \& Rachman, S. (2004). Symmetry, ordering and arranging compulsive behaviour. Behaviour Research and Therapy, 42, 893-913. doi:10.1016/j.brat.2003.07.001

Ramachandran, V. S., \& Hirstein, W. (1999). The science of art: A neurological theory of aesthetic experience. Journal of Consciousness Studies, 6(6-7), 15-51.

Reber, R., Schwarz, N., \& Winkielman, P. (2004). Processing fluency and aesthetic pleasure: Is beauty in the perceiver's processing experience? Personality and Social Psychology Review, 8, 364-382.doi:10.1207/s15327957pspr0804_3

Redies, C., Amirshahi, S. A., Koch, M., \& Denzler, J. (2012). PHOG-derived aesthetic measures applied to color photographs of artworks, natural scenes and objects. ECCV 2012 Workshops and Demonstrations, Part I. Lecture Notes in Computer Science, 7583, 522-531. doi:10.1007/978-3-642-33863-2_54 
Redies, C., Brachmann, A., \& Hayn-Leichsenring, G. U. (2015). Changes of statistical properties during the creation of graphic artworks. Art \& Perception, 3, 93-116. doi:10.1163/22134913-00002017

Redies, C., Brachmann, A., \& Wagemans, J. (2017). High entropy of edge orientations characterizes viusal artworks from diverse cultural backgrounds. Vision Research, 133, 130-144. doi:10.1016/j.visres.2017.02.004

Redies, C., Hänisch, J., Blickhan, M., \& Denzler, J. (2007). Artists portray human faces with the Fourier statistics of complex natural scenes. Network: Computation in Neural Systems, 18, 235-248. doi:10.1080/09548980701574496

Redies, C., Hasenstein, J., \& Denzler, J. (2007). Fractal-like image statistics in visual art: similarity to natural scenes. Spatial Vision, 21, 137-148. doi:10.1163/156856807782753921

Rentfrow, P. J., \& Gosling, S. D. (2003). The do re mi's of everyday life: The structure and personality correlates of music preferences. Journal of Personality and Social Psychology, 84, 1236-1256. doi:10.1037/0022-3514.84.6.1236

Rist, J. M. (1967). Plotinus: The road to reality. Cambridge, England: Cambridge University Press.

Rump, E. E. (1968). Is there a general factor of preference for complexity? Perception \& Psychophysics, 3, 346-348. doi:10.3758/BF03212482

Spehar, B., Clifford, C. W. G., Newell, B. R., \& Taylor, R. P. (2003). Universal aesthetics of fractals. Computers \& Graphics, 27, 813-820. doi:10.1016/S0097-8493(03)00154-7

Spehar, B., \& van Tonder, G. J. (2017). Koffka's aesthetic Gestalt. Leonardo, 50, 53-57. doi:10.1162/LEON_a_01020

Spehar, B., Walker, N., \& Taylor, R. P. (2016). Taxonomy of individual variations in aesthetic responses to fractal patterns. Frontiers in Human Neuroscience, 10, 350. doi:10.3389/fnhum.2016.00350

Sherman, A., Grabowecky, M., \& Suzuki, S. (2015). In the working memory of the beholder: Art appreciation is enhanced when visual complexity is compatible with working memory. Journal of Experimental Psychology: Human Perception and Performance, 41, 898-903. doi:10.1037/a0039314

Stephens, K. D., \& Hoffman, D. D. (2016). On visual texture preference: Can an ecological model explain why people like some textures more than others? Perception, 45, 527551. doi:10.1177/0301006616629026 
Street, N., Forsythe, A. M., Reilly, R., Taylor, R., \& Helmy, M. S. (2016). A complex story: Universal preference vs. individual differences shaping aesthetic response to fractals patterns. Frontiers in Human Neuroscience, 10, 213. doi:10.3389/fnhum.2016.00213

Swami, V., \& Furnham, A. (2012). The effects of symmetry and personality on aesthetic preferences. Imagination, Cognition and Personality, 32, 41-57. doi:10.2190/IC.32.1.d

Taylor, R. E., \& Eisenman, R. (1964). Perception and production of complexity by creative art students. The Journal of Psychology, 57, 239-242. doi:10.1080/00223980.1964.9916693

Taylor, C., \& Franklin, A. (2012). The relationship between color-object associations and color preference: Further investigation of ecological valence theory. Psychonomic Bulletin \& Review, 19, 190-197. doi:10.3758/s13423-012-0222-1

Taylor, R. P., Spehar, B., Van Donkelaar, P., \& Hagerhall, C. M. (2011). Perceptual and physiological responses to Jackson Pollock's fractals. Frontiers in Human Neuroscience, 5, 60. doi:10.3389/fnhum.2011.00060

Thompson, M. M., Naccarato, M. E., Parker, K. C. H., \& Moskowitz, G. B. (2001). The Personal Need for Structure (PNS) and Personal Fear of Invalidity (PFI) scales: Historical perspectives, present applications and future directions. In G. Moskowitz (Ed.), Cognitive social psychology: The Princeton symposium on the legacy and future of social cognition (pp. 19-39). Mahwah, NJ: Erlbaum.

Tinio, P. P. L., \& Leder, H. (2009). Just how stable are stable aesthetic features? Symmetry, complexity, and the jaws of massive familiarization. Acta Psychologica, 130, 241250. doi:10.1016/j.actpsy.2009.01.001

Van de Cruys, S., \& Wagemans, J. (2011). Putting reward in art: A tentative prediction error account of visual art. $i$-Perception, 2, 1035-1062. doi:10.1068/i0466aap

van der Helm, P. A., \& Leeuwenberg, E. L. J. (1996). Goodness of visual regularities: A nontransformational approach. Psychological Review, 103, 429-456. doi:10.1037/0033-295X.103.3.429

Vessel, E. A., \& Rubin, N. (2010). Beauty and the beholder: Highly individual taste for abstract, but not real-world images. Journal of Vision, 10(2), 18. doi:10.1167/10.2.18

Wagemans, J. (1997). Characteristics and models of human symmetry detection. Trends in Cognitive Sciences, 1, 346-352. doi:10.1016/S1364-6613(97)01105-4

Wagemans, J. (2011). Towards a new kind of experimental psycho-aesthetics? Reflections on the Parallellepipeda project. $i$-Perception, 2, 648-678. doi:10.1068/i0464aap 
Wagemans, J. (2018). Perceptual organization. In J. T. Wixted (Series Ed.) \& J. Serences (Vol. Ed.), The Stevens' Handbook of Experimental Psychology and Cognitive Neuroscience: Vol. 2. Sensation, Perception \& Attention (Chapter 18, pp. 803-872). Hoboken, NJ: John Wiley \& Sons, Inc.

Wagemans, J., Elder, J. H., Kubovy, M., Palmer, S. E., Peterson, M. A., Singh, M., \& von der Heydt, R. (2012). A century of Gestalt psychology in visual perception: I. Perceptual grouping and figure-ground organization. Psychological Bulletin, 138, 1172-1217. doi:10.1037/a0029333

Webster, D. M., \& Kruglanski, A. W. (1994). Individual differences in Need for Cognitive Closure. Journal of Personality and Social Psychology, 67, 1049-1062. doi:10.1037/0022-3514.67.6.1049

Weichselbaum, H., Leder, H., \& Ansorge, U. (2018). Implicit and explicit evaluation of visual symmetry as a function of art expertise. i-Perception. Advance online publication. doi:10.1177/2041669518761464

Westphal-Fitch, G., Huber, L., Gómez, J. C., \& Fitch, W. T. (2012). Production and perception rules underlying visual patterns: Effects of symmetry and hierarchy. Philosophical Transactions of the Royal Society, 367, 2007-2022. doi:10.1098/rstb.2012.0098

Wilson, A., \& Chatterjee, A. (2005). The assessment of preference for balance: Introducing a new test. Empirical Studies of the Arts, 23, 165-180. doi:10.2190/B1LR-MVF3-F36XXR64

Wundt, W. (1874). Grundzüge der physiologischen psychologie [Fundamentals of physiological psychology]. Leipzig, Germany: Wilhelm Engelmann. 